NBER WORKING PAPER SERIES

\title{
ANALYST PROMOTIONS WITHIN CREDIT RATING AGENCIES: ACCURACY OR BIAS?
}

\author{
Darren J. Kisgen \\ Matthew Osborn \\ Jonathan Reuter \\ Working Paper 22477 \\ http://www.nber.org/papers/w22477 \\ NATIONAL BUREAU OF ECONOMIC RESEARCH \\ 1050 Massachusetts Avenue \\ Cambridge, MA 02138 \\ August 2016, Revised August 2017
}

We thank Ramin Baghai (discussant), Nicole Boyson, Thomas Chemmanur, Jesse Cornaggia (discussant), Matti Keloharju, Jeffrey Pontiff, Vikram Nanda (discussant), Philip Strahan, brown bag participants at Boston College and Harvard, seminar participants at Rice University, University of Kansas, and University of Virginia, and conference participants at The Economics of Credit Rating Agencies, Credit Ratings and Information Intermediaries Conference (2015), Colorado Finance Summit (2015), Northeastern University Finance Conference (2016), and University of Connecticut Risk Management Conference (2016) for helpful questions and comments. Before collecting data on analyst career paths from LinkedIn.com, we submitted a proposal to Boston College's Institutional Review Board (IRB). We were granted an exemption from Boston College IRB review in accordance with 45 CFR 46.101 (b) 4. Our IRB Protocol Number is 16.192.01e. The views expressed in this article are solely those of the authors, who are responsible for the content, and do not necessarily represent the views of our employers. Any remaining errors are our own. The views expressed herein are those of the authors and do not necessarily reflect the views of the National Bureau of Economic Research.

NBER working papers are circulated for discussion and comment purposes. They have not been peer-reviewed or been subject to the review by the NBER Board of Directors that accompanies official NBER publications.

(C) 2016 by Darren J. Kisgen, Matthew Osborn, and Jonathan Reuter. All rights reserved. Short sections of text, not to exceed two paragraphs, may be quoted without explicit permission provided that full credit, including $\odot$ notice, is given to the source. 
Analyst Promotions within Credit Rating Agencies: Accuracy or Bias?

Darren J. Kisgen, Matthew Osborn, and Jonathan Reuter

NBER Working Paper No. 22477

August 2016, Revised August 2017

JEL No. G14,G24,G28

\section{ABSTRACT}

We examine whether credit rating agencies reward accurate or biased analysts. Using data collected from Moody's corporate debt credit reports, we find that Moody's is more likely to promote analysts who are accurate, but less likely to promote analysts who downgrade frequently. Combined, analysts who are accurate but not overly negative are approximately twice as likely to get promoted. Further, analysts whose rating changes are more informative to the market are more likely to get promoted, unless their ratings changes cause large negative market reactions. Moody's balances a desire for accuracy with a desire to cater to its corporate clients.

Darren J. Kisgen

Boston College

Fulton Hall, Finance Department

140 Commonwealth Av.

Chestnut Hill, MA 02467

Kisgen@bc.edu

Matthew Osborn 3409 Wilson Blvd, Unit 611

Arlington, VA 22201

m.g.osborn@gmail.com
Jonathan Reuter

Carroll School of Management

Boston College

224B Fulton Hall

140 Commonwealth Avenue

Chestnut Hill, MA 02467

and NBER

reuterj@bc.edu 


\section{Introduction}

While credit ratings play an important role in bond markets and institutional investing, their objectivity has been under scrutiny for years. ${ }^{1}$ Corporate bond ratings provide a summary assessment of a firm's credit quality that can be used by investors and regulators to assess risk. However, the structure of the industry provides the potential for conflicts of interest, not least because issuers of bonds typically pay rating agencies for the ratings on their bonds. While much research has focused on the quality of corporate and mortgage backed security ratings (e.g., Ashcraft, Goldsmith-Pinkham, and Vickery (2010); Becker and Milbourn (2011); Griffin and Tang (2012)), as yet little research has focused on the employees of credit rating agencies. ${ }^{2}$ In this paper, we infer Moody's preference for accurate versus biased ratings from the internal labor market outcomes of its analysts. Specifically, we combine data on analyst promotions and departures between 2002 and 2011 with analyst-level measures of ratings accuracy and bias and then explore how our measures correlate with subsequent career outcomes. Doing so allows us to shed new light on the objective function of a major credit rating agency.

We collect data on Moody's analysts names and ranks from over 40,000 "announcement" and "ratings action" reports on corporate debt. We focus on analysts who rate corporate bonds for two reasons. First, with over $\$ 8.5$ trillion in outstanding U.S. corporate debt, this market segment is important to investors and regulators. ${ }^{3}$ Second, and most importantly, corporate bond ratings are the setting in which we might expect to find the strongest preference for accuracy from credit ratings agencies, because the incentive to reward accurate ratings are arguably

\footnotetext{
${ }^{1}$ See, for example, Cornaggia, Cornaggia, and Xia (2016) and Behr, Kisgen, and Taillard (2016).

${ }^{2}$ One notable exception is Fracassi, Petry and Tate (2016). In their paper, they identify credit rating analyst fixed effects and find that these effects are important for bond yields and corporate policy. We focus instead on linking rating characteristics to analyst promotions and departures.

${ }^{3}$ At the end of 2016, SIFMA valued outstanding corporate debt at $\$ 8.5$ trillion, outstanding mortgage related debt at $\$ 8.9$ trillion, and outstanding treasury debt at $\$ 13.9$ trillion.
} 
stronger for corporate bonds than for mortgage backed securities (e.g., Frenkel (2015)). Our final sample includes 177 Moody's analysts covering 1,843 firms. The lowest of the five analyst ranks is Analyst and the highest is Managing Director. We observe 102 promotions (increases in analyst rank between years $t-1$ and $t$ ) across 786 analyst years. Because we recognize that not all departures reflect forced exits, we collect data from LinkedIn.com on the career paths of the 75 analysts who stop authoring corporate credit reports during our sample period. We find 14 rotations into other divisions of Moody's and 16 employer changes that plausibly reflect external promotions, leaving us with 45 departures that plausibly reflect an unfavorable assessment of the analyst's ratings by Moody's.

To determine the role that accuracy plays in the 102 promotions and 45 departures, we construct three distinct measures of accurate ratings, each with its own advantages and disadvantages. Using three measures increases the likelihood of detecting any underlying preference of Moody's for accurate ratings. To increase precision and reduce measurement error, our preferred specifications combine the (binary) accuracy measures into an "Accuracy Index."

Our first measure of accuracy, "Stock Accurate," is based on the idea that more informative rating initiations and revisions should generate larger stock price reactions. We find that analysts whose rating initiations and revisions are associated with above-median stock price reactions in year $t-1$ (relative to those of other Moody's analysts, excluding earnings announcements, and adjusting for stock-level idiosyncratic volatility) are significantly more likely to be promoted and significantly less likely to depart in year $t$. While this finding is consistent with Moody's valuing accuracy, we recognize that Stock Accurate may also proxy for an analyst's external reputation, which may not perfectly correlate with accuracy. Our second measure of accuracy is based on whether the Moody's analyst is a ratings "leader" relative to his counterpart at S\&P. 
Specifically, if Moody's and S\&P disagree on the rating for firm $j$ in year $t-1$, and S\&P subsequently moves its rating toward Moody's rating (thereby validating the initial Moody's rating), we classify the Moody's analyst's rating as "leading." We classify an analyst as "Rating Accurate" when he has more leading ratings than the median Moody's analyst of the same rank in the same calendar year. We find that Rating Accurate analysts are also significantly more likely to experience positive career outcomes at Moody's. Our third measure of accuracy focuses on changes in bond yields. We identify an analyst as "Yield Accurate" if, when her rating for firm $j$ differs from S\&P's rating, firm j's bond yields move in the direction implied by the Moody's rating more often than not (e.g., if the Moody's rating was more negative than S\&P's rating, the yield subsequently increases). While the point estimates on Yield Accurate are economically significant, they are not statistically significant at conventional levels, perhaps because we are only able to calculate Yield Accurate for 55\% of our analyst-year observations. ${ }^{4}$

When we combine the accuracy measures into an "Accuracy Index," we find that a one standard deviation increase in accuracy increases the probability of positive career outcomes between $35 \%$ and $66 \%$, with the largest effects in the sample of analyst-years for which we can include Yield Accurate in the index. All of the differences are statistically significant at the $1 \%$ level. To the best of our knowledge, this is the first paper to show that Moody's rewards analysts who generate accurate corporate bond ratings.

Next, we examine whether promotions and departures are related to measures that might plausibly be associated with negative analyst bias (i.e., pessimism) or positive analyst bias (i.e., optimism). ${ }^{5}$ We measure the overall pessimism or optimism of analysts in two ways. First, we

\footnotetext{
${ }^{4}$ The missing observations primarily reflect missing bond yield data in TRACE. See Section IV.A.

${ }^{5}$ When we observe that Moody's rating for firm $j$ is higher than S\&P's rating, the difference could reflect a strategic decision by the Moody's analyst to inflate the rating or a genuine belief that the S\&P rating is
} 
evaluate the frequency that each analyst downgrades or upgrades relative to the $\mathrm{S} \& \mathrm{P}$ rating on a firm. Consider a firm that has a BBB rating from Moody's and an equivalent rating from S\&P. We view a Moody's analyst to be more negative if the analyst downgrades the rating to BBBbut $\mathrm{S} \& \mathrm{P}$ does not lower its rating (defining this as a "relative downgrade"). Using S\&P as a benchmark implicitly controls for changing firm fundamentals, reducing concerns about analyst selection bias. Using changes in ratings instead of levels of ratings also reduces concerns about a Moody's fixed effect or industry-analyst fixed effect. We define an analyst to have a negative (positive) bias when he has more relative downgrades (upgrades) in a year than the median analyst, conditional on having at least one downgrade (upgrade). We find that analysts with negative bias in year $t-1$ are approximately $30 \%$ less likely to experience positive career outcomes in year $t$. We do not find any significant effects for analysts that we classify as upgraders.

Our second approach to identifying analyst bias relies on the rating prediction model of Baghai, Servaes, and Tamayo (2014), which allows us to predict the rating for firm $j$ in year $t$ based on its fundamentals. We then compare each analyst's actual rating to the corresponding model predicted rating. We classify an analyst as having a negative bias if more of his ratings fall below the model predicted rating than above (the control group exhibits either no bias or positive bias). We find that analysts classified as "Model Predicted Pessimists" are approximately 35\% less likely to experience positive career outcomes. We also find that analysts classified as "Model Predicted Optimists" are more likely experience positive career outcomes, but this finding is only statistically significant at conventional levels in univariate specifications.

When we combine the two binary measures of negative bias into a "Pessimist Index," we

too low. Because we cannot distinguish between these situations, we refer to positive bias relative to either S\&P or a predictive ratings model as optimism and negative bias relative to either S\&P or a predictive ratings model as pessimism. To the extent that conservative analysts prefer to issue lower ratings, pessimism is indistinguishable from conservatism. 
find that a one standard deviation increase in this index implies that more pessimistic analysts are approximately $30 \%$ less likely to experience a positive career. This finding is statistically significant at the $1 \%$ level. In contrast, an "Optimist Index" based on upgrades and model predicted optimism is neither economically nor statistically significant. We conclude that analysts who exhibit a negative bias are less likely to experience positive career outcomes at Moody’s.

To determine the relative weights that Moody's places on accuracy versus pessimism, we include both indices in the same specification. We find that a one standard deviation in the Accuracy Index increases the likelihood of positive career outcomes by approximately $60 \%$, while a one standard deviation increase in the Pessimist Index decreases the likelihood of positive career outcomes by approximately $30 \% .{ }^{6}$ The patterns are quantitatively similar and remain statistically significant when we exclude career outcomes during the financial crisis (2008 and 2009), and when we limit the sample to the three junior-most analyst ranks. ${ }^{7}$

To shed additional light on Moody's preference for accuracy, we ask whether downgrades that generate large negative announcement returns are rewarded or punished by Moody's. Downgrades with a large negative announcement return indicate that the market has received significant new information from the analyst report, either due to the information content of the report itself or the overall reputation of the analyst. In either case, these downgrades arguably help identify the most accurate analysts in our sample. ${ }^{8}$ At the same time, because downgrades

\footnotetext{
${ }^{6}$ When we extend the specification to include the Optimist Index, the odds ratios on this third index are both economically and statistically indistinguishable from one. See Appendix Table A-3.

${ }^{7}$ As we highlight in Section III, all of the credit reports in our sample are signed by both a junior and a senior analyst. Estimating our main specification on the subsample of junior analysts minimizes concerns about the same rating appearing simultaneously in the accuracy and pessimist indices of two Moody's analysts.

${ }^{8}$ Large equity returns around a downgrade might also indicate the analyst was slow to respond to negative news. However, since the market reacts significantly to the downgrade, this does not represent a situation in which the rating was slower than the market, which is a typical complaint against rating agencies.
} 
highlighting significant problems with a firm's creditworthiness are the most likely to harm relations with issuers, Moody's may choose not to reward this outcome. We find that analysts who generate in year $t-1$ an abnormal equity return in the bottom quartile of the abnormal equity returns within our sample (after excluding downgrades that coincide with earnings announcements and adjusting for stock-level idiosyncratic volatility) are between $36 \%$ and 53\% less likely to experience a positive career outcome in year $t$. However, we continue to find that accurate analysts are significantly more likely to experience positive career outcomes. Consequently, while Moody's appears to value accurate ratings, it also appears to fault analysts whose downgrades trigger a large negative equity return, essentially treating these downgrades as another form of pessimism.

In our final set of tests, we shift our focus to firm coverage decisions within Moody's. We find that firms that are downgraded by a Moody's analyst in year $t-1$ are approximately $50 \%$ more likely to receive a new analyst in year $t$. This is true even when we exclude firms that require a new analyst because their former analyst departs from Moody's in year $t$. This finding complements our earlier findings that Moody's discourages pessimist ratings. ${ }^{9}$

Overall, our findings are consistent with Moody's valuing accuracy, but also wanting its analysts to avoid being overly pessimistic. These are precisely the patterns that we would expect to find if Moody's were incentivizing analysts to balance the conflicting preferences of investors and issuers. Our findings are broadly consistent with the findings of Hong and Kubik (2003), who relate movements of equity analysts between brokerage houses to the accuracy and bias of their earnings forecasts, using data between 1983 and 2000. The main difference-beyond the

Rather, a significant market reaction indicates that the rating was informative, and informing the market should correlate to an objective for ratings accuracy.

${ }^{9}$ While we find that Moody's is more likely to reassigns pessimistic analysts, we do not find (in unreported regressions) any evidence that the new analysts assigned less pessimistic ratings the following year. 
different types of analysts and time periods - is that Hong and Kubik (2003) emphasize the effect of external promotions on analyst behavior whereas we emphasize the effect of internal promotions and (less favorable) departures.

Endogeneity is frequently a concern in papers identifying empirical relationships outside a laboratory setting. In our case, the most likely concern would be that analysts are not randomly assigned to firms. For example, if lower quality analysts are assigned to lower quality firms, we might identify a relationship between downgrades and career outcomes that neglects the omitted variable of analyst quality. We attempt to address this concern in several ways. First, three of our five main measures match Moody's analysts' ratings to S\&P's ratings for the same firm (i.e., "Rating Accurate," "Yield Accurate," and "Downgrader"). For example, when we identify an analyst as downgrading more frequently, we focus only on cases where Moody's downgrades and $\mathrm{S} \& \mathrm{P}$ does not. If lower quality analysts are assigned to lower quality firms, any impact on downgrade frequency should cancel out, since lower quality analysts would be assigned to lower quality firms at both Moody's and S\&P. Further, we primarily study changes in ratings. While different quality analysts might be selected for different qualities of firms, it is less likely that different quality analysts would be selected for firms whose ratings are about to change. And finally, two of our measures are based on changes in market prices (i.e., "Stock Accurate" and "Yield Accurate"). If certain analysts are assigned to low quality firms, the low quality should be reflected in market prices at the time of assignment, rather than in subsequent price changes. 


\section{Hypothesis Development and Related Literature}

We test two broad hypotheses in this paper regarding the incentive systems within rating agencies. The first hypothesis is that rating agencies internalize the preferences of institutional investors (and government agencies) for accuracy, leading them to reward analysts whose ratings are more accurate. Rating agencies are primarily information providers and rely on their reputations for providing accurate information to drive their business. ${ }^{10}$ If the desire for accuracy is paramount to rating agencies, they will reward analysts who provide more accurate ratings on a timely basis. Furthermore, a rating agency that places too little weight on accuracy may eventually lose its Nationally Recognized Statistical Ratings Organization (NRSRO) status, resulting in dramatically lower expected revenues. Indeed, beginning in September 2007, the Securities and Exchange Commission (SEC) began conducting annual audits of NRSROs to determine whether each NRSRO adhered to its stated rating criteria. ${ }^{11}$

The null hypothesis is that ratings agencies do not value accuracy due to a lack of significant competition in the rating industry plus a payment model in which issuers pay for ratings. Regulations in the rating industry simultaneously increase barriers to entry and provide a guaranteed client base since many regulations for institutional bond investment depend on ratings. These regulations might lead rating agencies to place little weight on analyst accuracy in promotion and firing decisions. Kisgen and Strahan (2010) find that regulations based on ratings affect

\footnotetext{
${ }^{10}$ Bouvard and Levy (2013) and Frenkel (2015) both model rating agency profits as a function of accuracy. Bouvard and Levy argue that profitability is eventually decreasing in an agency's reputation for accuracy, because perfectly accurate ratings reduce revenues from lower-quality issuers. They also argue that when issuers are allowed to receive ratings from multiple agencies, competition between agencies weakens the return to developing a reputation for accuracy. Frenkel (2015) argues that biased ratings are more likely to arise when there are a small number of issuers that receive (and pay for) ratings on a large number of issues. The implication is that ratings for corporate bonds should be more accurate than ratings for mortgage backed securities, even within the same agency.

${ }^{11}$ We explore the impact of SEC audits on Moody's revealed preferences for accuracy versus bias in Section IV.E.
} 
a firm's cost of capital; this implies that firms have a material reason to care about their credit rating absent any information content of those ratings. Cornaggia and Cornaggia (2013) show that ratings agencies that are paid directly by investors (rather than by issuers) provide ratings that are timelier with regard to default likelihoods. Institutional investors that want to engage in regulatory arbitrage may also place less weight on accurate ratings if bond yields do not fully reflect the published ratings (e.g., Opp, Opp, and Harris (2013)).

The second hypothesis is that ratings agencies internalize the preferences of issuers for optimistic ratings, leading them to reward analysts whose ratings are more optimistic and to punish analysts whose ratings are more pessimistic. To attract new business (and increase revenue), rating agencies might forgo accuracy and offer positively biased ratings to attract clients. Institutional investors seeking higher yielding bonds than they would otherwise have access to due to regulations may also push for inflated ratings. Some contend that optimist ratings on mortgage backed securities contributed to the recent financial crisis (e.g., Griffin and Tang (2012)). With respect to corporate bonds, Behr, Kisgen, and Taillard (2016) find that entrenchment due to ratings regulations enacted in 1975 led to ratings inflation. Bongaerts, Cremers, and Goetzmann (2006) find that firms shop for ratings, especially when they have split ratings from Moody's and S\&P around the investment grade threshold. Fracassi, Petry and Tate (2016) examine analyst bias and determine that some analysts' ratings are systematically optimistic or pessimistic. They show that this bias affects corporate decision making, which is consistent with the evidence in Kisgen (2006). Kedia, Rajgopal, and Zhou (2014, 2017) present evidence that Moody's awards differentially higher ratings to firms from which it was likely to earn more revenues after it became a publicly traded firm, or that were held in the portfolios of its two largest post-IPO shareholders (Berkshire Hathaway and Davis Selected Advisors). None of these studies, however, use 
the career outcomes of analysts to infer the preferences of credit rating agencies, which is our primary contribution.

To test these hypotheses, we focus on promotions and departures. A promotion is an unambiguously positive outcome for an analyst. A departure is likely to be a negative outcome, except when the analyst is leaving to take a higher-paying, more prestigious job. For example, Cornaggia, Cornaggia, and Xia (2016) find that some analysts leave their rating agency to work for banks for which they previously issued a favorable rating. It is important to note, however, that this possibility does not jeopardize the interpretation of our results. Regarding pessimism, if optimistic analysts are systematically recruited away from Moody's, we should find that optimism leads to departures and pessimism does not. We find the opposite to be true. Regarding accuracy, we find accurate analysts are more likely to be promoted and non-accurate analysts are more likely to depart. It is unclear why non-accurate analysts would be differentially recruited away from Moody's. Indeed, Kempf (2017) finds that analysts issuing more accurate ratings for nonagency securitized finance deals are more likely to leave for an investment bank. However, to account for departures that are positive career outcomes, we collect data on career outcomes from LinkedIn (described below). To more cleanly infer Moody's preferences for accuracy and bias from career outcomes, we exclude the small number of external promotions from our tests.

\section{Data}

We analyze hand-collected data on Moody's analyst coverage, ratings, promotions and departures. Our data come from over 40,000 "announcement" and "rating action" reports published on Moody's website between 2002 and 2011. Each report is linked to a firm and typically includes the names and current titles of two credit rating analysts (e.g., "John Smith, Senior Ana- 
lyst"). ${ }^{12}$ Aggregating this analyst information across all firms allows us to infer the timing of promotions within Moody's and departures from Moody's. Our review of all Moody's reports linked to Compustat firms during the sample period yields 342 unique analysts. From this initial list, we limit our sample to analysts with at least one year of tenure at Moody's and at least five analyst reports, where the analyst-rank spell begins in 2001 or later. ${ }^{13}$ We further limit our sample to analyst-years with at least one firm-level credit rating. It consists of 177 unique analysts covering 1,843 firms across 799 analyst-years and 9,557 firm-years.

We assume that an analyst is promoted in the year of the first report in which the analyst lists a new title. We identify 102 promotions. We do not find any instances of analyst demotions (i.e., where an analyst assumes a lower rank subsequent to obtaining a higher rank). To identify departures from Moody's, we begin by identifying 75 analysts whose names appear on multiple corporate credit reports in year $t-1$, but on zero corporate credit reports in year $t$. We then attempt to collect data on these 75 analysts' career paths from LinkedIn.com. Of the 54 analysts with LinkedIn accounts, we find that 16 leave Moody's for arguably more prestigious jobs (e.g., Blackstone Group, Goldman Sachs, or Merrill Lynch), 24 leave Moody's for comparable or less prestigious jobs (e.g., journalist, analyst at a foreign bank, analyst at A.M. Best, consultant at $\mathrm{S} \& \mathrm{P})$, and 14 rotate to another division within Moody's. The remaining 21 analysts appear on neither LinkedIn nor Moody's website, leading us to conclude that they also represent departures

\footnotetext{
${ }^{12} \mathrm{We}$ assume an analyst covers a firm if he signed at least one of the last two analyst reports specific to the firm. We deem a report specific to the firm, as opposed to a broader industry comment, if the report is linked to fewer than four firms. An analyst's coverage status expires when a new analyst begins covering the firm, when two years pass without the analyst writing a report that references the firm, or when the firm leaves the Compustat database.

${ }^{13}$ Moody's began publishing analyst reports on their website in 2000. Because we cannot determine the history of analyst-rank spells in effect at the start of the sample, we include only analyst-rank spells that begin in 2001 or later in our sample for analysis. This allows us to condition promotions and departures on time in rank. Our empirical analysis is based on credit reports issued between 2002 and 2011.
} 
to comparable or less prestigious firms. In the end, we classify 45 departures as "external demotions" and 14 rotations as neither a promotion nor a departure. Three of the 16 "external promotions" occur in the same calendar year as an internal promotion. Because our focus is on Moody's preferences for accuracy and bias, we retain these analyst-year observations as internal promotions, and we exclude the remaining 13 "external promotions" from the measure of departures our tests, reducing the number of analyst-year observations from 799 to 786.

We supplement our hand-collected data with firm- and event-level information from other standard sources. We obtain Moody's credit ratings data from Moody's Default Risk Service database. ${ }^{14}$ We then match each firm to Compustat, where we obtain firm-level financial information and the corresponding S\&P ratings for each firm. We compare Moody's rating for each firm to S\&P's rating by converting both rating scales to a numeric index, ranging from $1(\mathrm{Ca} / \mathrm{CC}$ or lower) to 20 (Aaa/AAA). For this index, ratings of 11 (Baa3/BBB-) and above are considered investment-grade, whereas ratings of $10(\mathrm{Ba} 1 / \mathrm{BB}+)$ and below are considered speculative-grade. We use daily stock return data from CRSP, and a Fama-French three factor model estimated over the prior three years of returns, to calculate three-day abnormal stock returns around the dates of ratings actions by analysts in the sample. We also use the daily stock return data to measure stock-level volatility. We use RavenPack to identify the dates of corporate earnings announcements. Finally, we use the FINRA Trade Reporting and Compliance Engine (TRACE) to measure firm-level changes in bond yields between year $t-1$ and year $t$. Since analysts cover multiple firms simultaneously, we aggregate all firm- and event-level data to the analyst-year level for our main empirical analysis as described in the next section.

To understand how Moody's coverage varies across analyst ranks, Table 1 reports ana-

\footnotetext{
${ }^{14}$ We use Moody's long term issuer rating. If unavailable, we use the Moody's Corporate Family rating.
} 
lyst-level summary statistics by rank. The five ranks are Analyst, Senior Analyst, Senior Credit Officer, Senior Vice President, and Managing Director. The average Moody's analyst rates 14.7 firms representing $\$ 161$ billion in aggregate firm assets. However, the number and average size of firms covered increases significantly with rank. The average Analyst covers 7.4 firms with an average firm size of $\$ 11.6$ billion in assets, while the average Managing Director covers 28.5 firms with an average firm size of $\$ 24.7$ billion in assets. Aggregate firm assets covered increases from \$34 billion for Analysts to $\$ 387$ billion for Managing Directors. These statistics reveal that analysts assume significantly broader firm coverage responsibility as they move up the ranks within Moody's. The average (and median) rating is consistently above the investment-grade cutoff, but also increases slightly with analyst rank. The fact that the average difference in ratings between Moody's and S\&P is negative confirms existing evidence that ratings issued by Moody's are slightly lower, on average, than those issued by S\&P (e.g., Jewell and Livingston (1999) and Bongaerts, Cremers, and Goetzmann (2012)).

Moody's corporate credit reports are signed by two analysts. Table 2 presents firm-level summary statistics on analyst coverage for our 9,557 firm-year observations. It reveals that larger and more highly rated firms are disproportionately assigned to Moody's more senior analysts. For instance, a Managing Director is the senior most rank assigned to $81.4 \%$ of firms rated A or higher, but only $55.5 \%$ of firms rated B or lower. Likewise, a Senior Vice President or higher is the junior most rank for $27.2 \%$ of firms rated A or higher, but only $14.2 \%$ of firms rated B or lower. Similar patterns hold for larger versus smaller firms. In other words, Moody's tends to assign senior analysts to cover potentially valuable relationships with larger, less risky firms (e.g., blue chips) while its junior analysts are assigned to smaller, riskier firms (e.g., junk issuers). More generally, Appendix Table A-1 reveals that the number of covered firms and level of 
covered assets increase with both analyst rank and years in rank, motivating us to estimate specifications that include analyst rank-by-years in rank fixed effects. ${ }^{15}$

The average number of analysts covering each firm is consistently greater than two because we are focusing on the number of distinct analysts who cover firm $j$ during calendar year $t$ and there is some firm-level turnover in analyst coverage within each calendar year. The fact that the average number of analysts is slightly higher among lower rated firms (2.4 versus 2.2) implies that analyst turnover rates are also slightly higher among these firms. The fact that each report is signed by both a junior and a senior analyst motivates us to estimate versions of our main specifications on the subsample of junior analysts.

Table 3 summarizes the frequency of Moody's analyst promotions and departures. As we describe above, we classify analyst $i$ as having been promoted in year $t$ if the analyst's title changes, for example, from Analyst to Senior Analyst during year $t$. We classify analyst $i$ as having departed from Moody's in year $t$ if we directly observe the departure on LinkedIn, or if the analyst signs one or more credit reports in year $t-1$, does not sign any credit reports in year $t$ or later, does not rotate to another division within Moody's, and does not appear on LinkedIn. Across the full sample, we observe promotion and departures in $13.0 \%$ and $6.6 \%$ of analystyears, respectively. Of the 177 unique analysts in the sample, $45.2 \%$ receive at least one promotion and 25.4\% depart from Moody's during the sample period.

The rate of both promotion and departures is highest in the two most junior positions, at $16.7 \%$ and $6.9 \%$ for an Analyst, and at $18.3 \%$ and $7.0 \%$ rate for a Senior Analyst. In addition, when we sort by the number of years in position across all levels (Panel A), we find that the likelihood of promotion is highest in the fourth and fifth years at $24.2 \%$ and $14.0 \%$ compared to

\footnotetext{
${ }^{15}$ We consider the possible link between accuracy, bias, and the level of covered assets in Section IV.D.
} 
$8.8 \%$ and $8.3 \%$ in the first and second years. Including analyst rank-by-years in rank fixed effects allows us to capture baseline differences in promotion and departure probabilities across analyst ranks and years in rank. Although we do not observe any discernable time-series patterns with respect to either promotions or departures when we sort the data by calendar year (Panel B), we also estimate specifications that include calendar year fixed effects.

\section{Results}

\section{A. Measures of accuracy and bias}

Our goal is to determine how ratings accuracy and bias influence the internal labor market outcomes of Moody's analysts. Evaluating these relations empirically requires us to distinguish accurate ratings from inaccurate ratings and positive bias from negative bias. However, studying Moody's analysts' ratings in isolation can raise potential measurement issues. For instance, an analyst's propensity to downgrade or upgrade firms may simply reflect relative performance of the firms and industries that the analyst covers. To address these types of concerns, we tend to compare Moody's analyst ratings to corresponding ratings from S\&P.

We construct three measures of Moody's analyst accuracy. The first is based on stock returns surrounding Moody's rating initiations and revisions ("Stock Accurate"), the second is based on the direction of S\&P rating revisions ("Rating Accurate"), and the third is based on changes in firm-level bond yields ("Yield Accurate"). For the stock return-based measure, we classify an analyst's rating as being accurate if the rated company's stock reacts significantly to Moody's ratings decision, based on a three factor abnormal return over a three day window around the rating announcement (excluding any rating announcements that coincide with earn- 
ings announcements). ${ }^{16}$ For each rating event, we calculate an accuracy "score" based on the corresponding abnormal return that accounts for the direction of the ratings changes. Specifically, we use the absolute value of the abnormal return for new ratings, the negative of the abnormal return for downgraded ratings, and the unadjusted abnormal return for upgraded ratings. We consider a higher score to reflect a more accurate ratings decision. Next, we aggregate the accuracy measure to a firm-year level by taking the maximum accuracy score within each firm-year. For example, if the Moody's analyst downgrades a firm twice within the same year, we use the downgrade with the highest return impact. We aggregate to analyst-year level by taking the median accuracy score across firms the analyst covered in that year. Finally, we set the "Stock Accurate" dummy variable equal to one for the half of analyst-year observations that have accuracy scores above the median for analysts within the full sample.

To construct "Rating Accurate," we focus on situations in which Moody's and S\&P publish different ratings for firm $j$ in year $t$. In these cases, when the S\&P analyst's next rating change reduces or eliminates this difference in ratings (i.e., when the $S \& P$ analyst follows the lead of the Moody's analyst), we classify the Moody's analyst's rating of firm $j$ in year $t$ as being "leading". We classify a Moody's analyst as "Accurate" using this measure when his percentage of "leading" ratings (as a percentage of firm assets) is greater than the median of all analysts in the sample (approximately $15 \%$ or more of the analyst's rated firm assets in year $t$ ). We set the accuracy dummy variable equal to zero if S\&P's ratings do not converge toward Moody's ratings, or if S\&P's and Moody's ratings differ for less than 15\% (the median) of the analyst's rated firm assets. Based on this measure, 313 of the 786 analyst-year observations involve a "Rating

\footnotetext{
${ }^{16}$ While this filter is intended to reduce the likelihood that abnormal returns are contaminated by the release of other value-relevant news, the impact of "Stock Accurate" on career outcomes is quantitatively similar to that estimated in earlier versions of the paper, which lacked this filter.
} 
Accurate" analyst.

Our final measure of accuracy is based on changes in firm-level bond yields. We again focus on situations where the Moody's analyst assigns a higher or lower rating to firm $j$ than the S\&P analyst. For each such rating, we then ask whether the firm's bond yield moves in the direction implied by the Moody's rating (e.g., the yield moves down in year $t$ when the Moody's rating is lower than the S\&P rating in year $t-1)$. We classify an analyst as "Yield Accurate" when the number of successful predictions is larger than the number of unsuccessful predictions. We calculate this measure for every analyst-year in which we can calculate the change in bond yields for at least one covered firm. However, because we are only able to calculate changes in bond yields in TRACE for a subset of covered firms, we are only able to calculate the "Yield Accurate" dummy variable for 436 of the 786 analyst-years within our sample. ${ }^{17}$

To increase precision and reduce measurement error, we also combine the (binary) accuracy measures into an "Accuracy Index." The Accuracy Index used throughout much of the paper sums the "Stock Accurate" and "Rating Accurate" dummy variables. It has a mean of 0.892 and a standard deviation of 0.742 . It is also highly persistent. Consider analysts for whom the Accuracy Index in year $t-1$ equals zero. In year $t$, the Accuracy Index equals zero for $54.0 \%$, one for $35.2 \%$, and two for $10.9 \%$. For analysts for whom the Accuracy Index in year t-1 years two, the corresponding percentages are 8.4\%, 46.1\%, and 45.5\%. We also consider an expanded Accuracy Index that includes "Yield Accurate" (and therefore ranges between zero and three). Among the 436 analyst-years for which this index is defined, the mean is 1.686 and the standard deviation is 0.868 .

\footnotetext{
${ }^{17}$ When calculating the "Yield Accurate" measure, we restrict our sample to bonds in TRACE that are not putable, convertible, payable-in-kind, do not have a subsidiary guarantee, and have a non-missing maturity date and a fixed coupon. Annual yield spread changes are computed from trades that fall in the December month of adjacent years.
} 
To construct our first measures of negative and positive analyst bias, we consider the frequency with which each analyst downgrades or upgrades relative to the S\&P rating on a firm. Consider a firm that has a BBB rating from S\&P and a (comparable) Baa2 rating from Moody's. If the Moody's analyst lowers her rating below Baa2 in year $t$ and the S\&P analyst does not lower her rating in year $t$, we classify the Moody's rating change as a downgrade. Focusing on downgrades relative to S\&P effectively controls for firm-level and industry-level shocks. If the analyst downgrades ratings on at least $15 \%$ of the rated firm assets, we set the "Downgrader" dummy variable equal to one for that analyst in year $t$. Similarly, if the analyst upgrades ratings on at least $15 \%$ of rated firm assets in year $t$ without corresponding upgrades by S\&P, we set the "Upgrader" dummy variable equal to one in year $t$. (The $15 \%$ cutoff was chosen so that approximately half of analysts who downgrade at least one firm are classified as downgraders and approximately half of analysts who upgrade at least one firm are classified as upgraders.) Based on this approach, 316 of the 786 analyst-year observations involve downgraders and 319 involve upgraders. Note that although a given analyst can be classified as both an "Upgrader" and a "Downgrader" in the same calendar year, this is rarely the case.

Our second measures of negative and positive analyst bias are based on the ratings prediction model of Baghai, Servaes, and Tamayo (2014), which allows us to predict the rating for firm $j$ in year $t$ based on its fundamentals. We then compare each analyst's actual rating to the corresponding model predicted rating. We classify an analyst as a "Model Predicted Pessimist" if more of his ratings fall below the model predicted rating than above (the control group exhibits either no bias or positive bias). This occurs in 201 (25.6\%) of the 786 analyst years. Similarly, we classify an analyst as a "Model Predicted Optimist" if more of his ratings fall above the model predicted rating than below. This occurs in 272 (34.6\%) of the 786 analyst years. (The remain- 
ing 313 (39.8\%) observations are classified as neither model predicted pessimists or optimists.) We construct a "Pessimist Index" by summing our "Downgrader" and "Model Predicted Pessimist" dummy variables, and we construct an analogous "Optimist Index." The "Pessimist Index" has a mean 0.469 and a standard deviation of 0.694 , while the "Optimist Index" has a mean of 0.474 and a standard deviation of 0.674 . We find that both indices are highly persistent. For example, for analysts with a Pessimist Index value in year $t-1$ of zero, in year $t$, the index equals zero for $62.0 \%$, one for $30.7 \%$, and two for $7.3 \%$. For analysts with a Pessimist Index value in year $\mathrm{t}-1$ of two, the corresponding percentages are $14.3 \%, 46.7 \%$, and $39.0 \%$. Our evidence of persistence with respect to pessimism and optimism is consistent with Fracassi, Petry and Tate's (2016) findings of analyst fixed effects.

\section{B. Does accuracy influence analyst career paths?}

We explore the effect of analyst accuracy on promotions and departures in Figure 1 and Table 4. Figure 1 plots the fraction of analysts who are promoted or depart from Moody's in year $t$ for the three different values of the Accuracy Index in year $t-1$. (We exclude the 13 departures that we classify as external promotions.) As the index increases from zero to two, the probability of promotion increases monotonically from $10.6 \%$ to $16.9 \%$ while the probability of departure decreases monotonically from $9.1 \%$ to $2.2 \%$. These patterns suggest that Moody's rewards analysts who generate accurate corporate bond ratings.

In Table 4, we report odds ratios from ordered logit regressions that classify promotions as positive outcomes and departures as negative outcomes. The independent variables of interest are the Accuracy Index and its components: the Stock Accurate, Rating Accurate, and Yield Accurate dummy variables. Panel A focuses on the full sample of analyst-year observations while Panel B focuses on the subsample for which we can calculate Yield Accurate. For each accuracy 
measure, we report both a univariate specification and a multivariate specification that includes a full set of calendar year and analyst rank-by-years in rank fixed effects.

Panel A reveals that the Stock Accurate and Rating Accurate dummy variables both predict positive career outcomes regardless of whether we focus on the univariate or the multivariate specification. Analysts classified as Stock Accurate are between 62\% and 66\% more likely to experience a positive career outcome the following year (significant at the 1-percent level), while analysts classified as Rating Accurate are between $38 \%$ and $47 \%$ more likely to do so (significant at the 10-percent level and below). The Accuracy Index, which sums the Stock Accurate and Rating Accurate dummy variables, also successfully predicts positive career outcomes.

Our findings are qualitatively similar in Panel B, where we extend the Accuracy Index to include the Yield Accurate dummy variable. The estimated odds ratios on the Stock Accurate and Rating Accurate dummy variables are slightly higher than in Panel A, and the significance levels are slightly lower. The odds ratios on Yield Accurate are economically significant, suggesting that Yield Accurate analysts are between $38 \%$ and 56\% more likely to experience a positive career outcome, but neither estimate is statistically significant at conventional levels. We conclude from Table 4 that Moody's internal labor market rewards analysts who issue more accurate corporate bond ratings. To the best of our knowledge, this is the first paper to demonstrate that Moody's values accurate corporate bond rating.

\section{Does bias influence analyst career paths?}

In this section, we focus on analyst-level measures of negative and positive. Figures 2 and 3 present univariate patterns for the Pessimist Index and Optimist Index, respectively. Figure 2 reveals that higher levels of pessimism in year $t-1$ are associated with lower probabilities of promotion and higher probabilities of departure in year $t$. Figure 3 reveals the highest probability 
of promotion and the lowest probability of departure when the Optimist Index equals two, but essentially no differences between these career outcomes when the index equals zero or one.

Panel A of Table 5 estimates ordered logits for the Pessimist Index and its components. Downgraders and Model Predicted Pessimists are both less likely to experience positive career outcomes in year $t$ than their peers. The odds ratios on the components range between 0.620 and 0.707 (significant at the 10-percent level and below), while the odds ratios on the Pessimist Index range between 0.701 and 0.724 (significant at the 5-percent level and below). The implication is that Moody's internal labor market appears to punish analysts that downgrade relative to S\&P or that issue ratings below those implied by our predicted ratings model.

Panel B estimates similar specifications for the Optimist Index and its components. The odds ratios on the Upgrader dummy variable are close to one (1.045 and 1.059) and statistically insignificant. Comparing the odds ratios in Panels A and B suggests that Moody's internal labor market punishes downgraders more than it rewards upgraders. The odds ratios on the Model Predicted Optimist dummy variable are economically larger, ranging from 1.404 in the univariate specification to 1.309 in the multivariate specification. However, we can only reject the hypothesis that the odds ratio equals one in the univariate specification, and only at the 10-percent level. Again, comparing Panels A and B, the implication appears to be that Moody's punishes model predicted pessimism more than it rewards model predicted optimism. The odds ratios on the Optimist Index vary between 1.137 and 1.182 , but are statistically indistinguishable from one. We conclude from Table 5 that Moody's internal labor market punishes pessimistic analysts more than it rewards optimistic analysts. ${ }^{18}$

\footnotetext{
${ }^{18}$ Although investment-grade issuers have an obvious preference for remaining investment grade, we do not find that Moody's punishes analysts any more severely for downgrading firms from investment grade to speculative grade. When we include a dummy variable indicating whether analyst $i$ downgraded one or
} 


\section{Does Moody's value accuracy, bias, or both?}

We begin investigating in Table 6 whether Moody's values accuracy, the absence of pessimism, or both. Panel A reports the fraction of analyst observations that depart from Moody's in year $t$ for different values of the accuracy and pessimism indices in year $t-1$. For each value of the Accuracy Index, higher values of the Pessimist Index are associated with higher departure probabilities. Similar, for each value of the Pessimist Index, lower values of the Accuracy Index are associated with higher departure probabilities. At the extremes, the probability of departure is $33.3 \%$ when the Accuracy Index equals zero and the Pessimist Index equals two and 0.0\% when the Accuracy Index equals two and the Pessimist Index equals one. Panel B, which instead reports the probability of promotion in year $t$, reinforces the possibility that Moody's internal labor market both rewards accuracy and punishes pessimism. In particular, the probability of promotion is $0.0 \%$ when the Accuracy Index equals zero and the Pessimist Index equals two and 36.1\% when the Accuracy Index equals two and the Pessimist Index equals one.

In Table 7, we estimate ordered logit regressions that include the Accuracy Index and the Pessimist Index. We also estimate logit regressions where the dependent variable equals one when the analyst is promoted in year $t$ and zero otherwise (thereby treating analysts who remain at Moody's and are not promoted the same as analysts who depart from Moody's). ${ }^{19}$ Panel A, which focuses on the full sample of analyst-year observations, contains our main findings. The

more firms from investment grade to speculative grade in year $t-1$ to specifications [1] and [4] of Table 7 Panel A, we find (in unreported regressions) that the odds ratio on this dummy variable are similar to the odds ratio on the Pessimist Index (between 0.723 and 0.784 ), but not statistically distinguish from one at conventional levels in either specification (p-values of 0.485 and 0.635 ). Note, however, that because only $4.5 \%$ of analyst-years involve a downgrade from investment grade to speculative grade, we are forced to define a downgrade from investment grade to speculative grade as an unconditional reductions in Moody's rating rather than as a reduction in Moody's rating relative to S\&P.

${ }^{19}$ The number of analyst-year observations falls when we estimate logit regressions because we exclude Managing Directors, for whom additional promotions are not possible. 
probability of more favorable career outcomes increases significantly with our analyst-level Accuracy Index and decreases significantly with our analyst-level Pessimist Index. In the ordered logits, all of the odds ratios are statistically distinguishable from one at the 1-percent level. In the logits, the odds ratios on the Accuracy Index are closer to one. For example, in the multivariate specifications, the odds ratio falls from 1.808 to 1.502 and statistically significance falls from the 1-percent level to the 5-percent level. These differences reflect the fact that less accurate analysts are more likely to depart, highlighting the advantage of focusing on both promotions and (nonfavorable) departures.

The findings in Panel A are robust to alternative samples and specifications. In Panel B, we exclude career outcomes for 2008 and 2009. Although our multivariate specifications already include calendar year fixed effects, Panel B allows for the possibility that Moody's revealed preferences for accuracy and bias were skewed during the financial crisis. The odds ratios on both indices are similar to those estimated over the full sample. In Panel C, we exclude Senior Vice Presidents and Managing Directors. There are two reasons to consider the sample of junior analysts. First, the fact that credit reports are signed by both junior and senior analysts implies that a given rating is being used to measure the accuracy and bias of two different analysts. Focusing on the sample of junior analysts greatly reduces the extent to which this is true. Second, if junior analysts have fewer managerial responsibilities, we might expect their promotions and departures to depend more strongly on the characteristics of their ratings. Alternatively, to increase oversight of junior analysts, Moody's might alternatively choose to hold senior analysts more accountable for the content of each credit report. The net effect is that the odds ratios and significance levels in Panel C are similar to those in Panel A.

We include two additional robustness tests in the Appendix. In Appendix Table A-3, we 
estimate specifications that include the Accuracy Index, Pessimist Index, and Optimist Index. While the odds ratios and significance levels on the Accuracy Index and Pessimist Index are similar to those estimated in Table 7, none of the odds ratios on the Optimist Index (which range between 0.827 and 1.033) are statistically distinguishable from one at conventional levels. Finally, in Appendix Table A-4, we replace the Optimist Index with the natural logarithm of rated assets in year $t-1$. To the extent that this variable reflects Moody's ongoing assessment on analyst ability, it is also likely to depend on the extent to which the analyst's ratings are accurate or pessimist. ${ }^{20}$ Indeed, everything else equal, we find that analysts with more rated assets in year $t-1$ are more likely to be promoted and less likely to depart in year $t$. For this reason, we prefer to exclude the measure from our main tests in Table 7. However, even controlling for the log of rated assets, we continue to find that accurate ratings are rewarded and pessimistic ratings are punished. In the ordered logit specifications, the odds ratios on the Accuracy Index and Pessimist Index are similar to those in Tables 7 and A-3 and consistently statistically significant from one at the 1-percent level. In the logit specifications, the odds ratios on the Accuracy Index fall slightly, but remain statistically significant at the 10-percent level and below. Overall, we conclude that Moody's internal labor market punishes pessimism more than it rewards optimism.

\footnotetext{
${ }^{20}$ While our focus has always been on analyst promotions and departures, we explored the possibility that accurate analysts might gain covered firms and covered assets at the same time that pessimist analysts lose them. We find a positive correlation (in unreported regressions) between the Accuracy Index and the dollar value of covered assets, but it is economically modest and only statistically significant at the 10percent level. Moreover, there is essentially no correlation between the pessimist index and the dollar value of covered assets or between the levels of the accuracy and pessimist indices and changes in the number of covered firms. In other words, the impact of accuracy and bias on the level of covered assets appears to operate indirectly, through an increased probability of promotion and a decreased probability of exit, rather than as an incremental reward within rank and years in rank.
} 


\section{E. Time-series variation in weights on accuracy and bias?}

The SEC began conducting annual audits of NRSROs in September 2007. Its stated goal was not to determine whether published ratings were accurate or biased relative to an absolute standard but rather to determine whether published ratings accurately reflected each firm's stated methodology and criteria. ${ }^{21}$ In this section, we ask whether the weight that Moody's placed on accurate ratings was different in years with annual audits (2008-2011) than it was earlier (20022007). The prospect of annual audits may have prompted Moody's to increase the weight placed on accurate ratings in promotion and departure decisions. On the other hand, given the SEC's focus on internal consistency rather than absolute standards, the audits may have prompted Moody's either not to change the weight placed on accurate ratings or to decrease it. In Table 8, we report versions of our main specifications in which we interact the Accuracy Index and Pessimism Index with Pre 2008 and Post 2007 dummy variables. (We also include either the Pre 2008 and Post 2007 dummy variables or the full set of calendar year fixed effects.) The odds ratio associated with the Accuracy Index falls significantly during the Post 2007 period. In ordered logit specification [2], the odds ratio falls from 2.286 to 1.513 . In logit specification [4], it falls from 2.117 to 1.135 . Both reductions are economically significant. The reduction in the logit specification is also significant at the 10-percent level. In other words, we find suggestive evidence that Moody's responded to the annual SEC audits by placing less weight on objective measures of accuracy in its promotion decisions.

Of course, at around the same time as these new audits, the financial crises occurred, which put rating agencies under further scrutiny. This additional scrutiny might arguably lead to

\footnotetext{
${ }^{21}$ We thank Abe Losice, former SEC auditor, for describing the criteria used to evaluate NRSRO ratings.
} 
a greater emphasis on accuracy by rating agencies; however, our evidence does not support this argument.

\section{F. Accuracy versus extreme equity market reactions to rating decisions}

To shed additional light on the extent to which Moody's values accuracy, we examine whether the stock market announcement returns in the three days around a credit report in year $t$ 1 predict analyst promotions or departures in year $t^{22}$ On the one hand, analysts may be rewarded for reports that convey new information about default risk to market participants, even if that information is negative. On the other hand, analysts may be punished for reports that significantly reduce the market capitalization of Moody's clients. To distinguish between these two possibilities, we focus on the most negative announcement returns (after scaling by firm-level volatility and excluding three day windows that include firm earnings announcements).

The initial set of ordered logit and logit specifications in Table 9 replicate specifications from Table 7. The new independent variable in the remaining specifications equals one if at least one of the analyst's announcement returns in year $t-1$ was in the bottom quartile of all announcement returns in our sample $(-9.7 \%$ and below). We find strong evidence that low abnormal returns are associated with less favorable career outcomes, suggesting that Moody's faults those analysts whose downgrades most surprise the market. However, we also continue to find that Moody's rewards accuracy, with odds ratios that are even further above one. One interpretation of these patterns, in the spirit of Opp, Opp, and Harris' (2013) political economy model of rating agencies, is that Moody's is catering to those issuers and investors with a preference for gradual ratings adjustments.

\footnotetext{
${ }^{22}$ Jorion, Liu, and Shi (2005) also focus on a three-day event window centered on the date of the rating change. By including day $t-1$, we capture any announcement effect that might arise if the rating change leaks one day early.
} 


\section{G. Does bias influence analyst reassignment?}

In Table 10, we explore whether Moody's is more likely to reassign analysts when firms have negatively biased ratings. Analyst reassignment is a more common and less extreme outcome than analyst departure, providing us with an additional way to infer the level of Moody's aversion to pessimistic ratings. We evaluate analyst reassignment at the firm-year level. Our dependent variable is a binary variable indicating whether Moody's replaces one or both of the analysts in year $t$ who covered the firm in year $t-1$. To the extent that Moody's seeks to discourage pessimistic ratings, or that issuers respond to pessimistic ratings by lobbying Moody's for new analysts, we expect to observe analyst reassignment more often when Moody's rating are more pessimistic.

The independent variables in Table 10 are analogous to those used in Panel A of Table 5, except that they are defined at the firm level. Downgrader equals one if Moody's downgraded firm $j$ in year $t-1$ and $\mathrm{S} \& \mathrm{P}$ did not do the same, and zero otherwise. Model Predicted Pessimist equals one if Moody's rating for firm $j$ in year $t-1$ was below that predicted by the Baghai, Servaes, and Tamayo (2014) ratings model, and zero otherwise. We find that firms whose ratings were downgraded in year $t-1$ are $52 \%$ more likely to receive a new analyst in year $t$ (significant at the 1-percent level), but do not find any effect for model predicted pessimism. ${ }^{23}$ When we combine the two firm-level dummy variables into a Pessimist Index, we find that the odds ratio is significantly greater than one (significant at the 1-percent level). This finding is robust to the inclusion of industry-by-calendar year fixed effects, and to the exclusion of firms covered by analysts that depart Moody's in year $t$. Overall, our findings in Table 10 complement our earlier finding that downgraders are less likely to experience positive career outcomes at Moody's.

\footnotetext{
${ }^{23}$ In unreported regressions, we find that ratings are less likely to rebound in the year following a downgrade when a new analyst is assigned to the firm.
} 


\section{Conclusion}

To shed new light on the behavior of credit rating agencies, we examine the career paths of corporate credit rating analysts within Moody's. Focusing on outcomes within Moody's internal labor market provides us with a unique opportunity to infer Moody's preferences for accuracy and bias. Focusing on corporate credit ratings provides us with a setting in which accuracy is likely to be valued by institutional investors. Indeed, we find that accurate analysts are more likely to be promoted and less likely to depart. This finding holds for multiple measures of accuracy and subsamples, and is strongest when we estimate specifications that consider the effect of accuracy on the likelihood of both positive and negative career outcomes. However, we also find that analysts who downgrade more frequently, who assign ratings below those predicted by a ratings model, and whose downgrades are associated with large negative market reactions are significantly less likely to experience positive career outcomes within Moody's. Furthermore, we find that Moody's is more likely to assign new analysts to firms with pessimistic ratings from existing analysts. Because we find that Moody's rewards accurate analysts but also punishes pessimistic analysts, we conclude that Moody's internal labor market incentivizes analysts to consider the conflicting preferences of investors and issuers. While our findings that Moody's values accuracy are both novel and encouraging, the preference for upwardly biased ratings suggests that there is still room for improvement. 


\section{References}

Ashcraft, Adam, Paul Goldsmith-Pinkham, and James Vickery (2010). MBS ratings and the mortgage credit boom. SSRN Working Paper \#1615613.

Baghai, Ramin, Henri Servaes, and Ane Tamayo (2014). Have rating agencies become more conservative? Journal of Finance 69(5), 1961-2005.

Behr, Patrick, Darren Kisgen, and Jerome Taillard (2016). Did government regulations lower credit rating quality? Management Science, forthcoming.

Bongaerts, Dion, Martijn Cremers, and William Goetzmann (2012). Tiebreaker: Certification and multiple credit ratings. Journal of Finance 67(1), 113-152.

Becker, Bo, and Todd Milbourn (2011). How did increased competition affect credit ratings? Journal of Financial Economics 101, 493-514.

Bouvard, Matthieu, and Raphael Levy (2015). Two-sided reputation in certification markets. Working paper.

Cornaggia, Jess, and Kimberly Cornaggia (2013). Estimating the costs of issuer-paid credit ratings. Review of Financial Studies 26(9), 2229-2269.

Cornaggia, Jess, Kimberly Cornaggia, and Han Xia (2016). Revolving doors on Wall Street. Journal of Financial Economics 120(2), 400-419.

Fracassi, Cesare, Stefan Petry, and Geoffrey Tate (2016). Does rating analyst subjectivity affect corporate debt pricing? Journal of Financial Economics 120 (3), 514-538.

Frenkel, Sivan (2015). Repeated interaction and rating inflation: A model of double reputation. American Economic Journal: Microeconomics 7(1): 250-280.

Griffin, John, and Dragon Tang (2012). Did subjectivity play a role in CDO credit ratings? Journal of Finance 67(4): 1293-1328.

Hong, Harrison, and Jeffrey Kubik (2003). Analyzing the analysts: Career concerns and biased earnings forecasts. Journal of Finance 58(1), 313-351.

Jewell, Jeff, and Miles Livingston (1999). A comparison of bond ratings from Moody's, S\&P, and Fitch IBCA. Financial Markets, Institutions, and Instruments 8(4): 1-45.

Jorion, Philippe, Zhu Liu, and Charles Shi (2005). Informational effects of regulation FD: Evidence from rating agencies. Journal of Finance Economics 76(2), 309-330.

Kedia, Simi, Shivaram Rajgopal, and Xing Zhou (2014). Did going public impair Moody's credit ratings? Journal of Finance Economics 114(2), 293-315. 
Kedia, Simi, Shivaram Rajgopal, and Xing Zhou (2017). Large shareholders and credit ratings. Journal of Finance Economics 124(3), 632-653.

Kempf, Elisabeth (2017). The job rating game: The effects of revolving doors on analyst incentives. SSRN Working Paper \#2893903.

Kisgen, Darren (2006). Credit ratings and capital structure. Journal of Finance 41(3), 10351072.

Kisgen, Darren, and Philip Strahan (2010). Do regulations based on credit ratings affect a firm's cost of capital? Review of Financial Studies 23(12), 4324-4347.

Opp, Christian, Marcus Opp, and Milton Harris (2013). Rating agencies in the face of regulation. Journal of Financial Economics 108(1), 46-61. 
Figure 1. Univariate Evidence on Influence of Accuracy on Career Outcomes

This Figure plots the fraction of analysts that promoted by Moody's or departing from Moody's in year $t$, for different values of the "Accuracy Index." We summarize the dummy variables underlying this index in Appendix Table A-2.

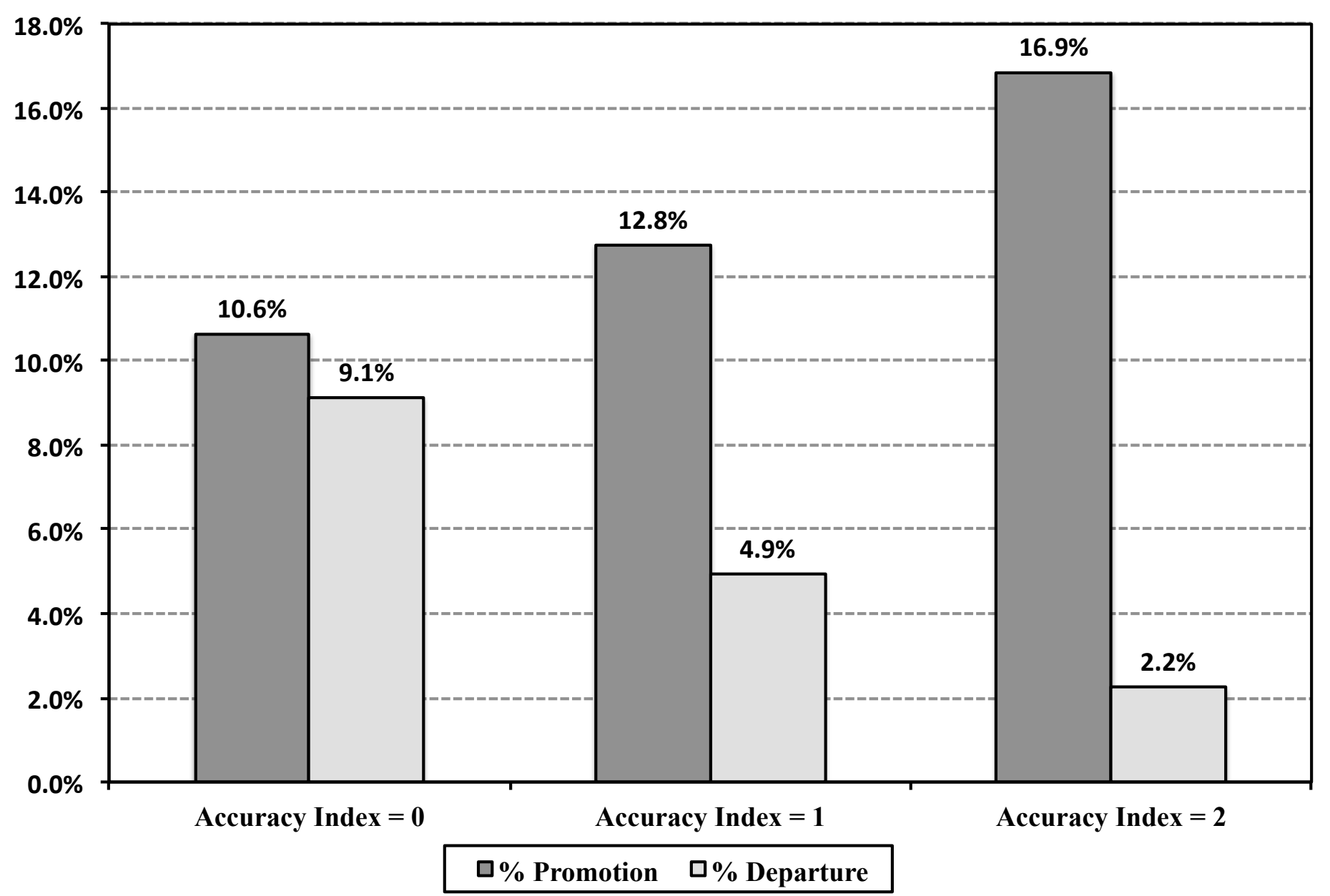


Figure 2. Univariate Evidence on Influence of Pessimism on Career Outcomes

This Figure plots the fraction of analysts that promoted by Moody's or departing from Moody's in year $t$, for different values of the "Pessimist Index." We summarize the dummy variables underlying this index in Appendix Table A-2.

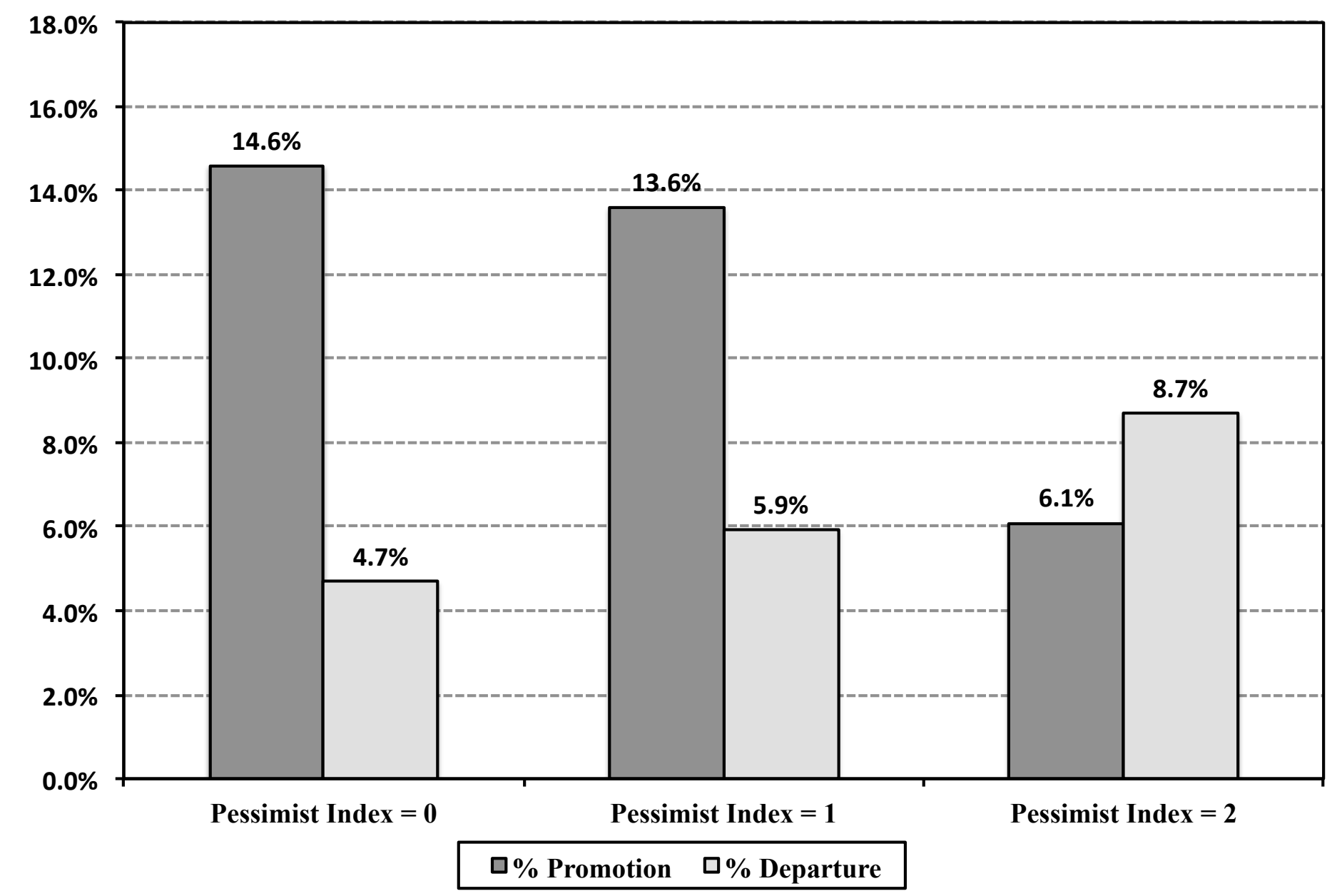


Figure 3. Univariate Evidence on Influence of Optimism on Career Outcomes

This Figure plots the fraction of analysts that promoted by Moody's or departing from Moody's in year $t$, for different values of the "Optimist Index." We summarize the dummy variables underlying this index in Appendix Table A-2.

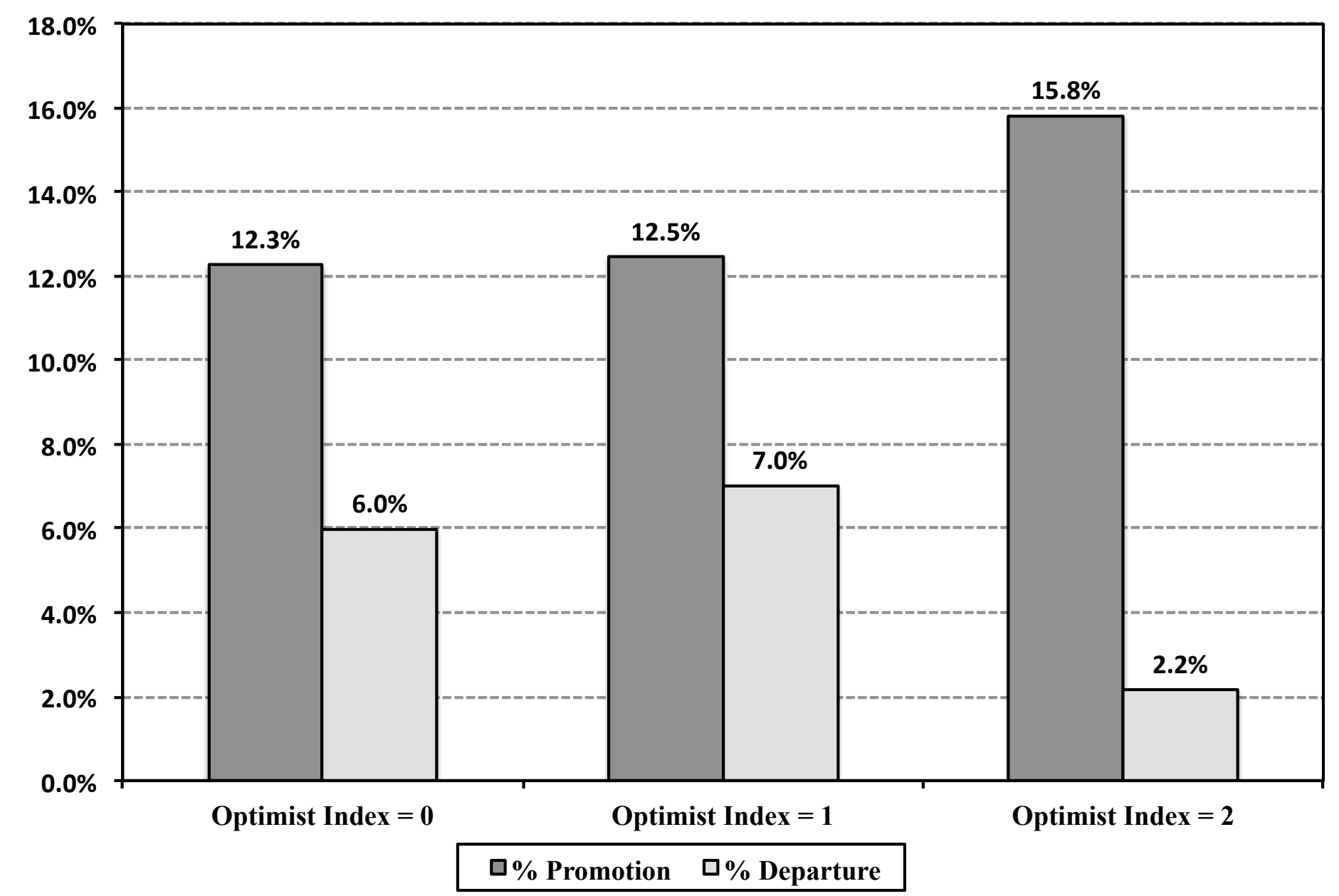


Table 1

Analyst-Level Summary Statistics

This table summarizes how the number and types of firms that analysts cover varies with analyst rank. We report statistics for all analystyears and separately for each (beginning of year) rank within Moody's. "Analyst" is the junior most rank and "Managing Director" is the senior most rank. The table reports means and medians for the number of firms covered with an issuer-level Moody's credit rating, the average asset size of rated firms, the aggregate asset size of rated firms, as well as the average rating level and ratings notch difference from S\&P. Credit rating notch levels range from 1 (Ca or lower) to 20 (Aaa), where 10 is equivalent to a Moody's rating of Ba1.

\begin{tabular}{|c|c|c|c|c|c|c|c|}
\hline \multirow[b]{3}{*}{ Variable } & & \multicolumn{6}{|c|}{ Analyst Rank } \\
\hline & & All Levels & Analyst & $\begin{array}{c}\text { Senior } \\
\text { Analyst }\end{array}$ & $\begin{array}{l}\text { Senior } \\
\text { Credit } \\
\text { Officer }\end{array}$ & $\begin{array}{c}\text { Senior } \\
\text { Vice } \\
\text { President }\end{array}$ & $\begin{array}{c}\text { Managing } \\
\text { Director }\end{array}$ \\
\hline & & $\mathbf{N}=786$ & $N=144$ & $\mathrm{~N}=\mathbf{2 2 9}$ & $\mathbf{N}=158$ & $\mathbf{N}=170$ & $\mathbf{N}=\mathbf{8 5}$ \\
\hline \multirow{2}{*}{ Number Rated Firms } & Mean & 14.7 & 7.4 & 9.2 & 9.9 & 25.8 & 28.5 \\
\hline & Median & 8.0 & 7.0 & 9.0 & 8.0 & 13.0 & 7.0 \\
\hline \multirow[t]{2}{*}{ Mean Firm Assets [Mill. \$] } & Mean & $\$ 20,976$ & $\$ 11,591$ & $\$ 17,964$ & $\$ 30,704$ & $\$ 22,219$ & $\$ 24,710$ \\
\hline & Median & $\$ 8,190$ & $\$ 3,086$ & $\$ 6,804$ & $\$ 10,232$ & $\$ 9,302$ & $\$ 13,549$ \\
\hline \multirow[t]{2}{*}{ Aggregate Rated Assets [Mill. \$] } & Mean & $\$ 161,643$ & $\$ 34,178$ & $\$ 92,880$ & $\$ 119,278$ & $\$ 293,276$ & $\$ 386,508$ \\
\hline & Median & $\$ 64,611$ & $\$ 17,538$ & $\$ 52,492$ & $\$ 78,910$ & $\$ 159,836$ & $\$ 231,683$ \\
\hline \multirow[t]{2}{*}{ Moody's Credit Rating } & Mean & 9.2 & 8.7 & 8.9 & 10.1 & 8.9 & 9.8 \\
\hline & Median & 8.0 & 8.0 & 8.0 & 9.0 & 8.0 & 9.0 \\
\hline \multirow[t]{2}{*}{ Mean Difference from S\&P } & Mean & -0.22 & -0.17 & -0.28 & -0.24 & -0.15 & -0.23 \\
\hline & Median & -0.20 & -0.20 & -0.29 & -0.20 & -0.13 & -0.13 \\
\hline
\end{tabular}


Table 2

Issuer Characteristics and Analyst Ranks

This table reveals that larger and more highly rated firms tend to be covered by more senior analysts. The unit of observation is firm $j$ in year $t$ and the sample is limited to rated issuers covered by Moody's analysts between 2002 and 2011. We report the fraction of firm-years where the "Senior Most Analyst" is a Managing Director, Senior Vice President, or below. We also report the fraction of firm-years where the "Junior Most Analyst" is an Analyst, Senior Analyst, Senior Credit Officer, or above. In each case, percentages sum to 100. Note that while the typical credit report is signed by two analysts, the average number of analysts is consistently greater than two because we are focusing on the number of distinct analysts who covered firm $j$ in calendar year $t$ and there is some turnover in analyst coverage within each calendar year.

\begin{tabular}{|c|c|c|c|c|c|c|c|c|c|}
\hline & \multirow{3}{*}{$\begin{array}{c}\text { All Firm- } \\
\text { Years }\end{array}$} & \multicolumn{4}{|c|}{ Firm Credit Rating } & \multicolumn{4}{|c|}{ Firm Asset Size Quartile } \\
\hline & & $\begin{array}{c}\text { B or } \\
\text { Lower }\end{array}$ & Baa & $\mathbf{B a}$ & $\begin{array}{c}\text { A or } \\
\text { Higher }\end{array}$ & $\begin{array}{c}\text { 1st } \\
\text { Quartile }\end{array}$ & $\begin{array}{c}\text { 2nd } \\
\text { Quartile }\end{array}$ & $\begin{array}{c}\text { 3rd } \\
\text { Quartile }\end{array}$ & $\begin{array}{c}\text { 4th } \\
\text { Quartile }\end{array}$ \\
\hline & & $\mathrm{N}=\mathbf{3 , 0 8 1}$ & $N=2,067$ & $N=716$ & $\mathrm{~N}=523$ & $\mathrm{~N}=2,365$ & $N=2,364$ & $N=2,364$ & $\mathrm{~N}=\mathbf{2 , 3 6 4}$ \\
\hline Number of Analysts & 2.4 & 2.4 & 2.4 & 2.2 & 2.2 & 2.3 & 2.4 & 2.4 & 2.4 \\
\hline \multicolumn{10}{|l|}{ Senior Most Analyst: } \\
\hline Managing Director & $69.7 \%$ & $55.5 \%$ & $66.5 \%$ & $88.3 \%$ & $81.4 \%$ & $49.6 \%$ & $66.5 \%$ & $77.9 \%$ & $84.8 \%$ \\
\hline Senior Vice President & $27.5 \%$ & $39.3 \%$ & $31.6 \%$ & $9.6 \%$ & $16.9 \%$ & $43.8 \%$ & $31.3 \%$ & $20.8 \%$ & $14.2 \%$ \\
\hline SCO or Lower & $2.8 \%$ & $5.2 \%$ & $2.0 \%$ & $2.1 \%$ & $1.7 \%$ & $6.6 \%$ & $2.3 \%$ & $1.2 \%$ & $1.0 \%$ \\
\hline \multicolumn{10}{|l|}{ Junior Most Analyst: } \\
\hline SVP or Higher & $18.5 \%$ & $14.2 \%$ & $17.4 \%$ & $20.5 \%$ & $27.2 \%$ & $12.3 \%$ & $15.3 \%$ & $18.5 \%$ & $27.8 \%$ \\
\hline Senior Credit Officer & $24.3 \%$ & $19.9 \%$ & $20.4 \%$ & $25.4 \%$ & $31.4 \%$ & $18.0 \%$ & $22.5 \%$ & $27.1 \%$ & $30.0 \%$ \\
\hline Senior Analyst & $39.1 \%$ & $42.0 \%$ & $43.0 \%$ & $42.7 \%$ & $29.5 \%$ & $39.7 \%$ & $41.8 \%$ & $41.5 \%$ & $33.4 \%$ \\
\hline Analyst & $18.1 \%$ & $23.9 \%$ & $19.1 \%$ & $11.3 \%$ & $11.9 \%$ & $30.0 \%$ & $20.5 \%$ & $12.9 \%$ & $8.8 \%$ \\
\hline
\end{tabular}


Table 3

Frequency of Analyst Promotion and Departure

This table summarizes the frequency of promotions and departures for Moody's analysts. The column "\% Promoted" reports the percentage of analyst-years with a promotion to a higher rank. The column "\% Depart" reports the percentage of analyst-years where the analyst departs from Moody's during the year (excluding the 13 observations where we classify the departure as an external promotion). We report promotion and departure percentages for all analyst-years and separately for each (beginning of year) rank within Moody's. "Analyst" is the junior most rank and "Managing Director" is the senior most rank. Panel A reports percentages by the number of years the analyst has remained in the current rank. Panel B reports percentages by calendar year. The Total Analyst-Years row reports the average fraction of observations that are promoted or depart, either overall or within rank. The Total Analysts row reports that fraction of analysts that are promoted at least once or depart, either overall or within rank. Of the 177 unique analysts in our sample, 52 have held the rank of Analyst, 83 have held the rank of Senior Analyst, 57 have held the rank of Senior Credit Officer, 42 have held the rank of Senior Vice President, and 24 have held the rank of Managing Director.

\begin{tabular}{|c|c|c|c|c|c|c|c|c|c|c|c|c|}
\hline & \multicolumn{3}{|c|}{ All Levels } & \multicolumn{2}{|c|}{ Analyst } & \multicolumn{2}{|c|}{ Senior Analyst } & \multicolumn{2}{|c|}{$\begin{array}{c}\text { Senior Credit } \\
\text { Officer }\end{array}$} & \multicolumn{2}{|c|}{$\begin{array}{c}\text { Senior } \\
\text { Vice President }\end{array}$} & \multirow{3}{*}{$\begin{array}{c}\begin{array}{c}\text { Managing } \\
\text { Director }\end{array} \\
\mathbf{N}=\mathbf{8 5} \\
\% \\
\text { Depart }\end{array}$} \\
\hline & \multicolumn{3}{|c|}{$N=786$} & \multicolumn{2}{|c|}{$N=144$} & \multicolumn{2}{|c|}{$N=229$} & \multicolumn{2}{|c|}{$N=158$} & \multicolumn{2}{|c|}{$\mathrm{N}=170$} & \\
\hline & $\begin{array}{l}\text { Analyst- } \\
\text { Years }\end{array}$ & $\begin{array}{c}\% \\
\text { Promoted }\end{array}$ & $\begin{array}{c}\% \\
\text { Depart }\end{array}$ & $\begin{array}{c}\% \\
\text { Promoted }\end{array}$ & $\begin{array}{c}\% \\
\text { Depart }\end{array}$ & $\begin{array}{c}\% \\
\text { Promoted }\end{array}$ & $\begin{array}{c}\% \\
\text { Depart }\end{array}$ & $\begin{array}{c}\% \\
\text { Promoted }\end{array}$ & $\begin{array}{c}\% \\
\text { Depart }\end{array}$ & $\begin{array}{c}\% \\
\text { Promoted }\end{array}$ & $\begin{array}{c}\% \\
\text { Depart }\end{array}$ & \\
\hline \multicolumn{13}{|c|}{ Panel A: Years in Rank } \\
\hline 1 Year & 125 & $8.8 \%$ & $4.0 \%$ & $20.0 \%$ & $0.0 \%$ & $5.0 \%$ & $10.0 \%$ & $12.2 \%$ & $6.1 \%$ & $9.1 \%$ & $0.0 \%$ & $0.0 \%$ \\
\hline 2 Years & 206 & $8.3 \%$ & $5.3 \%$ & $2.2 \%$ & $8.7 \%$ & $10.1 \%$ & $4.3 \%$ & $20.5 \%$ & $5.1 \%$ & $3.1 \%$ & $6.3 \%$ & $0.0 \%$ \\
\hline 3 Years & 156 & $12.8 \%$ & $7.1 \%$ & $8.1 \%$ & $8.1 \%$ & $21.8 \%$ & $9.1 \%$ & $16.0 \%$ & $8.0 \%$ & $3.8 \%$ & $3.8 \%$ & $0.0 \%$ \\
\hline 4 Years & 120 & $24.2 \%$ & $5.8 \%$ & $27.6 \%$ & $6.9 \%$ & $43.2 \%$ & $8.1 \%$ & $11.1 \%$ & $5.6 \%$ & $13.0 \%$ & $0.0 \%$ & $7.7 \%$ \\
\hline $5+$ Years & 179 & $14.0 \%$ & $6.1 \%$ & $40.7 \%$ & $3.7 \%$ & $12.5 \%$ & $6.3 \%$ & $11.1 \%$ & $3.7 \%$ & $8.9 \%$ & $5.4 \%$ & $14.3 \%$ \\
\hline \multicolumn{13}{|c|}{ Panel B: Calendar Year } \\
\hline 2002 & 25 & $8.0 \%$ & $8.0 \%$ & $0.0 \%$ & $0.0 \%$ & $0.0 \%$ & $14.3 \%$ & $25.0 \%$ & $12.5 \%$ & $0.0 \%$ & $0.0 \%$ & $0.0 \%$ \\
\hline 2003 & 41 & $14.6 \%$ & $2.4 \%$ & $0.0 \%$ & $0.0 \%$ & $27.3 \%$ & $0.0 \%$ & $9.1 \%$ & $0.0 \%$ & $18.2 \%$ & $9.1 \%$ & $0.0 \%$ \\
\hline 2004 & 54 & $14.8 \%$ & $11.1 \%$ & $28.6 \%$ & $14.3 \%$ & $21.4 \%$ & $14.3 \%$ & $13.3 \%$ & $20.0 \%$ & $9.1 \%$ & $0.0 \%$ & $0.0 \%$ \\
\hline 2005 & 63 & $11.1 \%$ & $3.2 \%$ & $14.3 \%$ & $14.3 \%$ & $16.7 \%$ & $0.0 \%$ & $21.4 \%$ & $7.1 \%$ & $0.0 \%$ & $0.0 \%$ & $0.0 \%$ \\
\hline 2006 & 85 & $10.6 \%$ & $3.5 \%$ & $12.5 \%$ & $6.3 \%$ & $10.3 \%$ & $6.9 \%$ & $23.1 \%$ & $0.0 \%$ & $5.9 \%$ & $0.0 \%$ & $0.0 \%$ \\
\hline 2007 & 102 & $15.7 \%$ & $6.9 \%$ & $9.5 \%$ & $0.0 \%$ & $25.0 \%$ & $11.1 \%$ & $23.1 \%$ & $0.0 \%$ & $9.5 \%$ & $0.0 \%$ & $27.3 \%$ \\
\hline 2008 & 111 & $13.5 \%$ & $7.2 \%$ & $18.5 \%$ & $7.4 \%$ & $18.8 \%$ & $9.4 \%$ & $15.8 \%$ & $5.3 \%$ & $4.5 \%$ & $4.5 \%$ & $9.1 \%$ \\
\hline 2009 & 112 & $13.4 \%$ & $5.4 \%$ & $20.0 \%$ & $8.0 \%$ & $16.7 \%$ & $3.3 \%$ & $8.7 \%$ & $4.3 \%$ & $12.5 \%$ & $8.3 \%$ & $0.0 \%$ \\
\hline 2010 & 96 & $16.7 \%$ & $4.2 \%$ & $35.3 \%$ & $0.0 \%$ & $19.2 \%$ & $11.5 \%$ & $14.3 \%$ & $4.8 \%$ & $9.1 \%$ & $0.0 \%$ & $0.0 \%$ \\
\hline 2011 & 97 & $8.2 \%$ & $6.2 \%$ & $5.9 \%$ & $17.6 \%$ & $19.2 \%$ & $0.0 \%$ & $4.8 \%$ & $4.8 \%$ & $4.8 \%$ & $9.5 \%$ & $0.0 \%$ \\
\hline $\begin{array}{c}\text { Total Analyst- } \\
\text { Years } \\
\end{array}$ & 786 & $13.0 \%$ & $5.7 \%$ & $16.7 \%$ & $6.9 \%$ & $18.3 \%$ & $7.0 \%$ & $14.6 \%$ & $5.7 \%$ & $7.6 \%$ & $3.5 \%$ & $4.7 \%$ \\
\hline Total Analysts & 177 & $45.2 \%$ & $25.4 \%$ & $46.2 \%$ & $19.2 \%$ & $50.6 \%$ & $19.3 \%$ & $40.4 \%$ & $15.8 \%$ & $31.0 \%$ & $14.3 \%$ & $16.7 \%$ \\
\hline
\end{tabular}


Table 4

\section{Does Accuracy Influence Career Paths?}

This table reports odds ratios from ordered logistic regressions of analyst-level measures of accuracy on career outcomes. After dropping the 13 analyst-year observations that we classify as external promotions, we code internal promotions as 1 and all other departures from Moody's as -1. Panel A focuses on the full sample of analyst-year observations. Panel B focuses on the subsample of analyst-years observations for which we can calculate the Yield Accurate dummy variable. In Panel A, the Accuracy Index is the sum of the Stock Accurate and Rating Accurate dummy variables. In Panel B, the Accuracy Index is the sum of the Stock Accurate, Rating Accurate, and Yield Accurate dummy variables. All of the independent variables are defined in Section IV.A. The multivariate specifications include calendar year fixed effects and analyst rank-by-years in rank fixed effects. We report the absolute values of Z-statistics below the odds ratios. ***,**, and * denote statistical significance at the 1 percent, 5 percent, and 10 percent levels, respectively, based on heteroskedasticity-robust standard errors that are clustered by analyst.

\begin{tabular}{|c|c|c|c|c|c|c|c|c|}
\hline \multicolumn{9}{|l|}{ Panel A. Full Sample of Analyst-Years } \\
\hline & \multicolumn{7}{|c|}{ Ordered Logit: Career Path $[t]$} & \\
\hline Explanatory Variables & {$[1]$} & {$[2]$} & {$[3]$} & & {$[4]$} & {$[5]$} & {$[6]$} & \\
\hline Accuracy Index [t-1] & $\begin{array}{c}1.474 * * * \\
(3.075)\end{array}$ & & & & $\begin{array}{c}1.464 * * * \\
(2.785)\end{array}$ & & & \\
\hline Stock Accurate [t-1] & & $\begin{array}{c}1.621 * * * \\
(2.632)\end{array}$ & & & & $\begin{array}{c}1.662 * * * \\
(2.655)\end{array}$ & & \\
\hline Rating Accurate [t-1] & & & $\begin{array}{c}1.465 * * \\
(2.146)\end{array}$ & & & & $\begin{array}{l}\text { 1.384* } \\
(1.695)\end{array}$ & \\
\hline Calendar Year FEs? & -- & -- & -- & & Yes & Yes & Yes & \\
\hline Analyst Rank * Years in Rank FEs? & -- & -- & -- & & Yes & Yes & Yes & \\
\hline$N$ & 786 & 786 & 786 & & 786 & 786 & 786 & \\
\hline Pseudo R-Squared & 0.010 & 0.007 & 0.005 & & 0.075 & 0.073 & 0.068 & \\
\hline \multicolumn{9}{|c|}{ Panel B. Subsample of Analyst-Years with Yield Accuracy measure } \\
\hline & \multicolumn{8}{|c|}{ Ordered Logit: Career Path $[t]$} \\
\hline Explanatory Variables & {$[1]$} & {$[2]$} & {$[3]$} & {$[4]$} & {$[5]$} & {$[6]$} & {$[7]$} & {$[8]$} \\
\hline Accuracy Index [t-1] & $\begin{array}{c}1.667 * * * \\
(3.004)\end{array}$ & & & & $\begin{array}{c}1.762 * * * \\
(3.284)\end{array}$ & & & \\
\hline Stock Accurate [t-1] & & $\begin{array}{c}2.137 * * * \\
(2.826)\end{array}$ & & & & $\begin{array}{c}\mathbf{2 . 2 6 3 * * *} \\
(2.880)\end{array}$ & & \\
\hline Rating Accurate [t-1] & & & $\begin{array}{l}\text { 1.573* } \\
(1.828)\end{array}$ & & & & $\begin{array}{l}\text { 1.643* } \\
(1.745)\end{array}$ & \\
\hline Yield Accurate [t-1] & & & & $\begin{array}{c}\mathbf{1 . 3 8 3} \\
(1.192)\end{array}$ & & & & $\begin{array}{c}\mathbf{1 . 5 6 8} \\
(1.580)\end{array}$ \\
\hline Calendar Year FEs? & -- & -- & -- & -- & Yes & Yes & Yes & Yes \\
\hline Analyst Rank * Years in Rank FEs? & -- & -- & -- & -- & Yes & Yes & Yes & Yes \\
\hline$N$ & 436 & 436 & 436 & 436 & 436 & 436 & 436 & 436 \\
\hline Pseudo R-Squared & 0.024 & 0.017 & 0.006 & 0.003 & 0.127 & 0.119 & 0.108 & 0.107 \\
\hline
\end{tabular}


Table 5

Does Bias Influence Career Paths?

This table reports odds ratios from ordered logistic regressions of analyst-level measures of negative and positive bias on career outcomes. After dropping the 13 analyst-year observations that we classify as external promotions, we code internal promotions as 1 and all other departures from Moody's as -1. Panel A focuses on the Pessimist Index and its components, the Downgrader and

Model Predicted Pessimist dummy variables. Panel B focuses on the Optimist Index and its components, the Upgrader and Model Predicted Optimist dummy variables. All of the independent variables are defined in Section IV.A. The multivariate specifications include calendar year fixed effects and analyst rank-by-years in rank fixed effects. We report the absolute values of Z-statistics below the odds ratios. ***,**, and * denote statistical significance at the 1 percent, 5 percent, and 10 percent levels, respectively, based on heteroskedasticity-robust standard errors that are clustered by analyst.

\begin{tabular}{|c|c|c|c|c|c|c|}
\hline \multicolumn{7}{|l|}{ Panel A. Pessimism } \\
\hline & \multicolumn{6}{|c|}{ Ordered Logit: Career Path [t] } \\
\hline Explanatory Variables & {$[1]$} & [2] & {$[3]$} & {$[4]$} & [5] & [6] \\
\hline Pessimist Index [t-1] & $\begin{array}{c}\mathbf{0 . 7 2 4} * * * \\
(2.589)\end{array}$ & & & $\begin{array}{c}\mathbf{0 . 7 0 1} * * \\
(2.488)\end{array}$ & & \\
\hline Downgrader [t-1] & & $\begin{array}{l}\mathbf{0 . 7 0 7 *} \\
(1.857)\end{array}$ & & & $\begin{array}{c}\mathbf{0 . 6 7 8 *} \\
(1.933)\end{array}$ & \\
\hline Model Predicted Pessimist [t-1] & & & $\begin{array}{c}\mathbf{0 . 6 4 4 * *} \\
(2.179)\end{array}$ & & & $\begin{array}{c}\mathbf{0 . 6 2 0} * * \\
(1.981)\end{array}$ \\
\hline Calendar Year FEs? & -- & -- & -- & Yes & Yes & Yes \\
\hline Analyst Rank * Years in Rank FEs? & -- & -- & -- & Yes & Yes & Yes \\
\hline$N$ & 786 & 786 & 786 & 786 & 786 & 786 \\
\hline Pseudo R-Squared & 0.007 & 0.004 & 0.005 & 0.073 & 0.070 & 0.070 \\
\hline \multicolumn{7}{|l|}{ Panel B. Optimist } \\
\hline & \multicolumn{6}{|c|}{ Ordered Logit: Career Path [t] } \\
\hline Explanatory Variables & [1] & {$[3]$} & {$[2]$} & {$[4]$} & [6] & [5] \\
\hline Optimist Index [t-1] & $\begin{array}{c}\mathbf{1 . 1 8 2} \\
(1.490)\end{array}$ & & & $\begin{array}{c}\mathbf{1 . 1 3 7} \\
(1.068)\end{array}$ & & \\
\hline Upgrader [t-1] & & $\begin{array}{c}\mathbf{1 . 0 5 9} \\
(0.343)\end{array}$ & & & $\begin{array}{c}\mathbf{1 . 0 4 5} \\
(0.241)\end{array}$ & \\
\hline Model Predicted Optimist [t-1] & & & $\begin{array}{l}1.404 * \\
(1.890)\end{array}$ & & & $\begin{array}{c}1.309 \\
(1.375)\end{array}$ \\
\hline Calendar Year FEs? & -- & -- & -- & Yes & Yes & Yes \\
\hline Analyst Rank * Years in Rank FEs? & -- & -- & -- & Yes & Yes & Yes \\
\hline$N$ & 786 & 786 & 786 & 786 & 786 & 786 \\
\hline Pseudo R-Squared & 0.002 & 0.000 & 0.003 & 0.067 & 0.066 & 0.067 \\
\hline
\end{tabular}




\section{Table 6}

Accuracy, Pessimism, and Career Outcomes

Panel A reports the fraction of analyst-year observations that depart from Moody's in year $t$ for different values of the Accuracy Index and Pessimist Index in year $t$-1. It is based on the full sample of analyst-year observations. Panel B reports the fraction of analyst-year observations that a promoted by Moody's in year $t$ for different values of the Accuracy Index and Pessimist Index in year t-1. It excludes Managing Directors because they are not eligible for promotion. In Panel A, more negative outcomes are shaded red. In Panel B, more positive outcomes are shaded darker blue.

\begin{tabular}{|c|c|c|c|c|c|c|c|c|c|}
\hline \multicolumn{5}{|c|}{ Panel A. Departures } & \multicolumn{5}{|c|}{ Panel B. Promotions } \\
\hline \multirow[b]{2}{*}{ Pessimist Index } & \multicolumn{4}{|c|}{ Accuracy Index } & \multicolumn{4}{|c|}{ Accuracy Index } & \multirow[b]{2}{*}{ ALL } \\
\hline & 0 & 1 & 2 & ALL & Pessimist Index & 0 & 1 & 2 & \\
\hline 2 & $33.3 \%$ & $8.9 \%$ & $3.4 \%$ & $8.7 \%$ & 2 & $0.0 \%$ & $5.0 \%$ & $9.6 \%$ & $6.9 \%$ \\
\hline 1 & $10.1 \%$ & $5.8 \%$ & $2.5 \%$ & $5.9 \%$ & 1 & $12.9 \%$ & $16.0 \%$ & $16.9 \%$ & $15.5 \%$ \\
\hline 0 & $7.1 \%$ & $3.1 \%$ & $0.0 \%$ & $4.7 \%$ & 0 & $12.2 \%$ & $15.6 \%$ & $36.1 \%$ & $16.1 \%$ \\
\hline ALL & $9.1 \%$ & $4.9 \%$ & $2.2 \%$ & $5.7 \%$ & ALL & $11.9 \%$ & $14.4 \%$ & $18.9 \%$ & $14.6 \%$ \\
\hline
\end{tabular}


Table 7

\section{Accuracy Versus Pessimism}

This table reports odds ratios from ordered logistic regressions of analyst-level measures of accuracy and bias on career outcomes. After dropping the 13 analyst-year observations that we classify as external promotions, we code internal promotions as 1 and all other departures from Moody's as -1. It also reports odds ratios from logistic regressions of accuracy and bias on internal promotions. Panel A focuses on the full sample of analyst-year observations. Panel B excludes career outcomes for 2008 and 2009. Panel C excludes Senior Vice Presidents and Managing Directors. All specifications include the Accuracy Index and the Pessimist Index, which are defined in Section IV.A. The multivariate specifications include calendar year fixed effects and analyst rank-by-years in rank fixed effects. We report the absolute values of Z-statistics below the odds ratios. ${ }^{* *},{ }^{* *}$, and $*$ denote statistical significance at the 1 percent, 5 percent, and 10 percent levels, respectively, based on heteroskedasticity-robust standard errors that are clustered by analyst.

\section{Panel A. Full Sample}

\begin{tabular}{lcccccc} 
& \multicolumn{2}{c}{ Ordered Logit: Career Path $[t]$} & & \multicolumn{2}{c}{ Logit: Promoted $[t]$} \\
\cline { 2 - 3 } \cline { 5 - 6 } Explanatory Variables & {$[1]$} & {$[2]$} & & {$[3]$} & \multicolumn{2}{c}{$[4]$} \\
\hline Accuracy Index [t-1] & $\mathbf{1 . 8 2 5 * * *}$ & $\mathbf{1 . 8 0 8 * * *}$ & & $\mathbf{1 . 5 7 3 * * *}$ & $\mathbf{1 . 5 0 2 * *}$ \\
& $(4.206)$ & $(3.883)$ & & $(2.806)$ & $(2.183)$ \\
Pessimist Index [t-1] & $\mathbf{0 . 5 6 9 * * *}$ & $\mathbf{0 . 5 5 6 * * *}$ & & $\mathbf{0 . 6 0 8 * * *}$ & $\mathbf{0 . 5 7 3 * * *}$ \\
& $(4.050)$ & $(3.781)$ & & $(2.826)$ & $(2.788)$ \\
Calendar Year FEs? & -- & Yes & & -- & Yes \\
Analyst Rank * Years in Rank FEs? & -- & Yes & & -- & Yes \\
$N$ & 786 & 786 & & 701 & 701 \\
Pseudo R-Squared & 0.028 & 0.091 & & 0.021 & 0.130 \\
\hline
\end{tabular}

Panel B. Excludes career outcomes for 2008 and 2009

\begin{tabular}{lcccccc} 
& \multicolumn{2}{c}{ Ordered Logit: Career Path [t] } & & \multicolumn{2}{c}{ Logit: Promoted [t] } \\
\cline { 2 - 3 } \cline { 5 - 6 } Explanatory Variables & {$[1]$} & {$[2]$} & & {$[3]$} & {$[4]$} \\
\hline Accuracy Index [t-1] & $\mathbf{1 . 9 8 0 * * *}$ & $\mathbf{1 . 9 1 9 * * * *}$ & & $\mathbf{1 . 6 6 6 * * *}$ & $\mathbf{1 . 5 6 7 * *}$ \\
& $(3.913)$ & $(3.533)$ & & $(2.701)$ & $(2.068)$ \\
Pessimist Index $[\mathrm{t}-1]$ & $\mathbf{0 . 5 6 8 * * *}$ & $\mathbf{0 . 5 5 7 * * *}$ & & $\mathbf{0 . 6 1 3} * *$ & $\mathbf{0 . 5 6 8 * *}$ \\
$N$ & $(3.336)$ & $(3.220)$ & & $(2.436)$ & $(2.483)$ \\
Pseudo R-Squared & 563 & 563 & & 499 & 480 \\
& 0.032 & 0.090 & & 0.024 & 0.122 \\
\hline
\end{tabular}

Panel C. Excludes Senior Vice Presidents (SVP) and Managing Directors (MD)

\begin{tabular}{lcccccc} 
& \multicolumn{2}{c}{ Ordered Logit: Career Path [t] } & & \multicolumn{2}{c}{ Logit: Promoted [t] } \\
\cline { 2 - 3 } \cline { 5 - 6 } Explanatory Variables & {$[1]$} & {$[2]$} & & {$[3]$} & {$[4]$} \\
\hline Accuracy Index [t-1] & $\mathbf{1 . 8 6 1 * * *}$ & $\mathbf{1 . 8 4 9} * * *$ & & $\mathbf{1 . 5 7 5}^{* * * *}$ & $\mathbf{1 . 5 0 8}^{* * *}$ \\
Pessimist Index [t-1] & $(4.008)$ & $(3.764)$ & & $(2.653)$ & $(2.112)$ \\
& $\mathbf{0 . 5 7 8 * * *}$ & $\mathbf{0 . 5 4 4 * * *}$ & & $\mathbf{0 . 6 7 1 * *}$ & $\mathbf{0 . 6 1 0} * *$ \\
$N$ & $(3.511)$ & $(3.457)$ & & $(2.171)$ & $(2.301)$ \\
Pseudo R-Squared & 531 & 531 & & 531 & 531 \\
& 0.031 & 0.085 & & 0.020 & 0.124 \\
\hline
\end{tabular}


Table 8

Do Weights on Accuracy Versus Pessimism Change in Response to Annual SEC Audits?

This table extends the ordered logistic regressions and logistic regressions in Table 7 Panel A to interact the Accuracy Index and Pessimist Index with pre-2008 and post-2007 dummy variables. We include but do not report the coefficients on the Pre 2008 dummy variable in specifications [1] and [3]. It also reports p-values from hypothesis tests that the odds ratios estimated for an index in 2002-2007 are equal to the odds ratios estimated for the same index in 2008-2011. The multivariate specifications include calendar year fixed effects and analyst rank-by-years in rank fixed effects. We report the absolute values of Z-statistics below the odds ratios. ${ }^{* *}, *^{* *}$, and $*$ denote statistical significance at the 1 percent, 5 percent, and 10 percent levels, respectively, based on heteroskedasticity-robust standard errors that are clustered by analyst.

\begin{tabular}{|c|c|c|c|c|}
\hline \multirow[b]{2}{*}{ Explanatory Variables } & \multicolumn{2}{|c|}{ Ordered Logit: Career Path [t] } & \multicolumn{2}{|c|}{ Logit: Promoted [t] } \\
\hline & {$[1]$} & {$[2]$} & [3] & {$[4]$} \\
\hline Accuracy Index [t-1] * Pre 2008 & $\begin{array}{c}2.235 * * * \\
(3.840)\end{array}$ & $\begin{array}{c}2.286 * * * \\
(3.835)\end{array}$ & $\begin{array}{c}2.173 * * * \\
(2.998)\end{array}$ & $\begin{array}{l}2.117 * * \\
(2.454)\end{array}$ \\
\hline Accuracy Index [t-1] * Post 2007 & $\begin{array}{l}1.532 * * \\
(2.443)\end{array}$ & $\begin{array}{l}\mathbf{1 . 5 1 3} * * \\
(2.361)\end{array}$ & $\begin{array}{c}\mathbf{1 . 2 0 1} \\
(0.936)\end{array}$ & $\begin{array}{c}\mathbf{1 . 1 3 5} \\
(0.554)\end{array}$ \\
\hline Pessimist Index [t-1] * Pre 2008 & $\begin{array}{c}\mathbf{0 . 5 3 6} * * * \\
(-3.160)\end{array}$ & $\begin{array}{c}\mathbf{0 . 5 1 4} * * * \\
(-3.172)\end{array}$ & $\begin{array}{l}\mathbf{0 . 5 4 6} * * \\
(-2.413)\end{array}$ & $\begin{array}{l}\mathbf{0 . 4 9 8} * * \\
(-2.382)\end{array}$ \\
\hline Pessimist Index [t-1] * Post 2007 & $\begin{array}{c}\mathbf{0 . 5 7 5} * * * \\
(-2.840)\end{array}$ & $\begin{array}{c}\mathbf{0 . 5 7 5} * * * \\
(-2.764)\end{array}$ & $\begin{array}{c}\mathbf{0 . 6 3 3 *} \\
(-1.810)\end{array}$ & $\begin{array}{c}\mathbf{0 . 6 2 8} * \\
(-1.676)\end{array}$ \\
\hline Ho: Accuracy Pre = Accuracy Post & 0.139 & 0.116 & 0.052 & 0.091 \\
\hline Ho: Pessimist Pre $=$ Pessimist Post & 0.798 & 0.698 & 0.682 & 0.566 \\
\hline Pre 2008 and Post 2007 FEs? & Yes & -- & Yes & -- \\
\hline Calendar Year FEs? & -- & Yes & -- & Yes \\
\hline Analyst Rank * Years in Rank FEs? & -- & Yes & -- & Yes \\
\hline$N$ & 786 & 786 & 701 & 701 \\
\hline Pseudo R-Squared & 0.030 & 0.035 & 0.027 & 0.135 \\
\hline
\end{tabular}


Table 9

\section{Career Outcomes and Extreme Announcement Returns}

This table extends the ordered logistic regressions and logistic returns in Table 7 Panel A to include the Low Abnormal Return dummy variable, which is defined in Section IV.F. The multivariate specifications include calendar year fixed effects and analyst rank-by-years in rank fixed effects. We report the absolute values of Z-statistics below the odds ratios. ${ }^{* * *},{ }^{* *}$, and $*$ denote statistical significance at the 1 percent, 5 percent, and 10 percent levels, respectively, based on heteroskedasticity-robust standard errors that are clustered by analyst.

\begin{tabular}{|c|c|c|c|c|c|c|}
\hline \multirow[b]{2}{*}{ Explanatory Variables } & \multicolumn{3}{|c|}{ Ordered Logit: Career Path [t] } & \multicolumn{3}{|c|}{ Logit: Promoted $[t]$} \\
\hline & {$[1]$} & {$[2]$} & [3] & [4] & {$[5]$} & [6] \\
\hline Accuracy Index [t-1] & $\begin{array}{c}1.825 * * * \\
(4.206)\end{array}$ & $\begin{array}{c}1.971 * * * \\
(4.388)\end{array}$ & $\begin{array}{c}1.971 * * * \\
(4.104)\end{array}$ & $\begin{array}{c}1.573 * * * \\
(2.806)\end{array}$ & $\begin{array}{c}1.725 * * * \\
(3.205)\end{array}$ & $\begin{array}{c}1.667 * * * \\
(2.620)\end{array}$ \\
\hline Pessimist Index [t-1] & $\begin{array}{c}\mathbf{0 . 5 6 9} * * * \\
(-4.050)\end{array}$ & $\begin{array}{c}\mathbf{0 . 5 8 5} * * * \\
(-3.835)\end{array}$ & $\begin{array}{c}\mathbf{0 . 5 7 2} * * * \\
(-3.581)\end{array}$ & $\begin{array}{c}\mathbf{0 . 6 0 8} * * * \\
(-2.826)\end{array}$ & $\begin{array}{c}\mathbf{0 . 6 3 6} * * * \\
(-2.585)\end{array}$ & $\begin{array}{l}\mathbf{0 . 6 0 1} * * \\
(-2.547)\end{array}$ \\
\hline Low Abnormal Return [t-1] & & $\begin{array}{l}\mathbf{0 . 6 4 0} * * \\
(-2.073)\end{array}$ & $\begin{array}{l}\mathbf{0 . 6 1 9} * * \\
(-1.964)\end{array}$ & & $\begin{array}{l}\mathbf{0 . 4 8 2 * * *} \\
(-2.230)\end{array}$ & $\begin{array}{l}\mathbf{0 . 4 6 4 * *} \\
(-2.160)\end{array}$ \\
\hline Calendar Year FEs? & -- & -- & Yes & -- & -- & Yes \\
\hline Analyst Rank * Years in Rank FEs? & -- & -- & Yes & -- & -- & Yes \\
\hline$N$ & 786 & 786 & 786 & 701 & 701 & 701 \\
\hline Pseudo R-Squared & 0.028 & 0.031 & 0.095 & 0.021 & 0.030 & 0.137 \\
\hline
\end{tabular}




\section{Table 10}

Does Ratings Bias Influence Analyst Reassignment?

This table reports odds ratios from logistic regressions that assess whether firms with negatively biased ratings are more likely to be assigned a new Moody's analyst than other issuers. The unit of observation is firm-year. For each firm-year covered by Moody's analysts in years $t$ and $t-1$, the dependent variable equals one if one or more of the analysts covering the firm in year $t$ was not covering the firm in year $t-1$. The independent variables are analogous to those in Panel A of Table 5, except that they are defined at the firm level. Downgrader equals one if Moody's downgraded the firm relative to S\&P in year t-1, and zero otherwise. Model Predicted Pessimist equals one if the Moody's rating is lower than that predicted by the rating prediction model of Ramin, Servaes, and Tamayo (2014). The Pessimist Index equals the sum of the Downgrader and Model Predicted Pessimist dummy variables. Columns [4] and [6] include a separate fixed effect for each of the 12 Fama French industries each calendar year. Columns [5] and [6] exclude firms covered by analysts in year t-1 that depart Moody's in year t. We report the absolute values of Z-statistics below the odds ratios. ${ }^{* *}, * *$, and $*$ denote statistical significance at the 1 percent, 5 percent, and 10 percent levels, respectively, based on heteroskedasticity-robust standard errors that are clustered by firm.

\begin{tabular}{|c|c|c|c|c|c|c|}
\hline \multirow[b]{2}{*}{ Explanatory Variables } & \multicolumn{6}{|c|}{$\begin{array}{l}\text { Logit: New Analyst }[\mathrm{t}] \\
\{\text { New Analyst Assigned to Firm }=1, \text { Otherwise }=0\}\end{array}$} \\
\hline & {$[1]$} & {$[2]$} & [3] & [4] & [5] & {$[6]$} \\
\hline Pessimist Index [t-1] & $\begin{array}{c}1.228 * * * \\
(4.009)\end{array}$ & & & $\begin{array}{c}1.204 * * * \\
(3.027)\end{array}$ & $\begin{array}{l}1.214 * * * \\
(3.531)\end{array}$ & $\begin{array}{c}1.233 * * * \\
(2.894)\end{array}$ \\
\hline Downgrader [t-1] & & $\begin{array}{l}1.522 * * * \\
(5.302)\end{array}$ & & & & \\
\hline Model Predicted Pessimist [t-1] & & & $\begin{array}{c}\mathbf{1 . 0 4 1} \\
(0.616)\end{array}$ & & & \\
\hline Industry-by-Calendar Year FEs? & -- & -- & -- & Yes & -- & Yes \\
\hline Excluding Analyst Departures & -- & -- & -- & -- & Yes & Yes \\
\hline$N$ & 5,440 & 5,440 & 5,440 & 4,081 & 4,545 & 3,287 \\
\hline Pseudo R-Squared & 0.002 & 0.004 & 0.000 & 0.002 & 0.002 & 0.003 \\
\hline
\end{tabular}




\section{Appendix Table A-1}

\section{Number of Rated Firms and Level of Rated Firm Assets by Analyst Rank and Years in Rank}

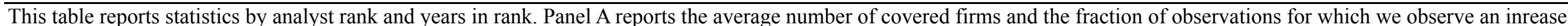
in the number of covered firms. Panel B reports the mean total assets of covered firms and mean change in total assets of covered firms. Panel C reports the number of analysts in each cell. The unexpectedly large number of covered firms for first-year Analysts is driven by 5 observations.

\section{Panel $A$.}

\begin{tabular}{|c|c|c|c|c|c|c|c|c|c|c|}
\hline \multirow[b]{3}{*}{ Analyst Rank } & \multirow{2}{*}{\multicolumn{5}{|c|}{$\frac{\text { Mean Number of Covered Firms }}{\text { Years in Rank }}$}} & \multirow{2}{*}{\multicolumn{5}{|c|}{$\begin{array}{c}\text { Fraction with Increase in Number of Covered Firms? } \\
\text { Years in Rank }\end{array}$}} \\
\hline & & & & & & & & & & \\
\hline & 1 & 2 & 3 & 4 & $5+$ & 1 & 2 & 3 & 4 & $5+$ \\
\hline Analyst & 16.6 & 6.1 & 7.5 & 7.6 & 7.3 & $100.0 \%$ & $65.2 \%$ & $62.2 \%$ & $31.0 \%$ & $33.3 \%$ \\
\hline Senior Analyst & 8.5 & 9.3 & 10.1 & 10.0 & 7.9 & $50.0 \%$ & $69.6 \%$ & $49.1 \%$ & $37.8 \%$ & $27.1 \%$ \\
\hline Senior Credit Officer & 13.0 & 8.4 & 9.8 & 9.0 & 6.9 & $34.7 \%$ & $33.3 \%$ & $20.0 \%$ & $38.9 \%$ & $33.3 \%$ \\
\hline Senior Vice President & 24.1 & 25.0 & 29.8 & 29.4 & 23.8 & $69.7 \%$ & $50.0 \%$ & $30.8 \%$ & $47.8 \%$ & $26.8 \%$ \\
\hline Managing Director & 33.0 & 30.2 & 35.3 & 33.4 & 16.0 & $38.9 \%$ & $55.0 \%$ & $46.2 \%$ & $23.1 \%$ & $4.8 \%$ \\
\hline
\end{tabular}

\section{Panel B.}

\begin{tabular}{|c|c|c|c|c|c|c|c|c|c|c|}
\hline \multirow[b]{2}{*}{ Analyst Rank } & \multicolumn{5}{|c|}{$\begin{array}{c}\text { Mean Total Assets of Covered Firms } \\
\text { Years in Rank }\end{array}$} & \multicolumn{5}{|c|}{ Mean Change in Total Assets of Covered Firms } \\
\hline & 1 & 2 & 3 & 4 & $5+$ & 1 & 2 & 3 & 4 & $5+$ \\
\hline Analyst & 21.5 & 27.3 & 39.2 & 37.6 & 37.4 & 10.2 & 19.0 & 6.7 & 6.9 & -2.9 \\
\hline Senior Analyst & 101.2 & 84.5 & 97.8 & 79.6 & 106.2 & 33.7 & 27.6 & 15.6 & -10.1 & 6.3 \\
\hline Senior Credit Officer & 136.5 & 136.6 & 112.1 & 77.9 & 98.4 & 50.1 & 8.8 & 15.4 & 6.9 & 14.7 \\
\hline Senior Vice President & 182.6 & 232.5 & 294.8 & 383.4 & 357.4 & 53.0 & 70.8 & 37.1 & 45.4 & 34.2 \\
\hline Managing Director & 462.3 & 388.8 & 407.0 & 504.4 & 229.9 & 122.7 & 55.4 & 52.5 & 161.7 & -26.2 \\
\hline
\end{tabular}

\section{Panel C.}

\begin{tabular}{lrrrrrr} 
& \multicolumn{9}{c}{ Count } & \\
\cline { 2 - 5 } \multicolumn{1}{c}{ Analyst Rank } & \multicolumn{1}{c}{ Years in Rank } & TOTAL \\
\cline { 2 - 5 } & \multicolumn{1}{c}{ 1 } & \multicolumn{1}{c}{3} & 4 & $5+$ & 144 \\
Analyst & 5 & 46 & 37 & 29 & 27 & 229 \\
Senior Analyst & 20 & 69 & 55 & 37 & 48 & 158 \\
Senior Credit Officer & 49 & 39 & 25 & 18 & 27 & 170 \\
Senior Vice President & 33 & 32 & 26 & 23 & 56 & 85 \\
Managing Director & 18 & 20 & 13 & 13 & 21 & 786 \\
TOTAL & 125 & 206 & 156 & 120 & 179 & \\
\hline
\end{tabular}


Appendix Table A-2

Measures of Accuracy and Bias

This table summarizes the frequency of Moody's analyst promotions and departures for our three measures of accuracy, two measures of negative bias, two measures of positive bias, and measure of low abnormal equity returns. Across the columns, we report statistics for all analyst-years and separately for each (beginning of year) rank within Moody's. "Analyst" is the junior most rank and "Managing Director" is the senior most rank. Panel A reports the percentage of analyst-years in which analysts that we classify as accurate or biased are promoted; it excludes Managing Directors because they are not eligible for promotion. Panel B reports comparable percentages for departures from Moody's; it includes Managing Directors but excludes the 13 analysts-year observations where we classify the departure as an external promotion. We define the low abnormal equity return dummy variable in Section IV.F and the other dummy variables in Section IV.A.

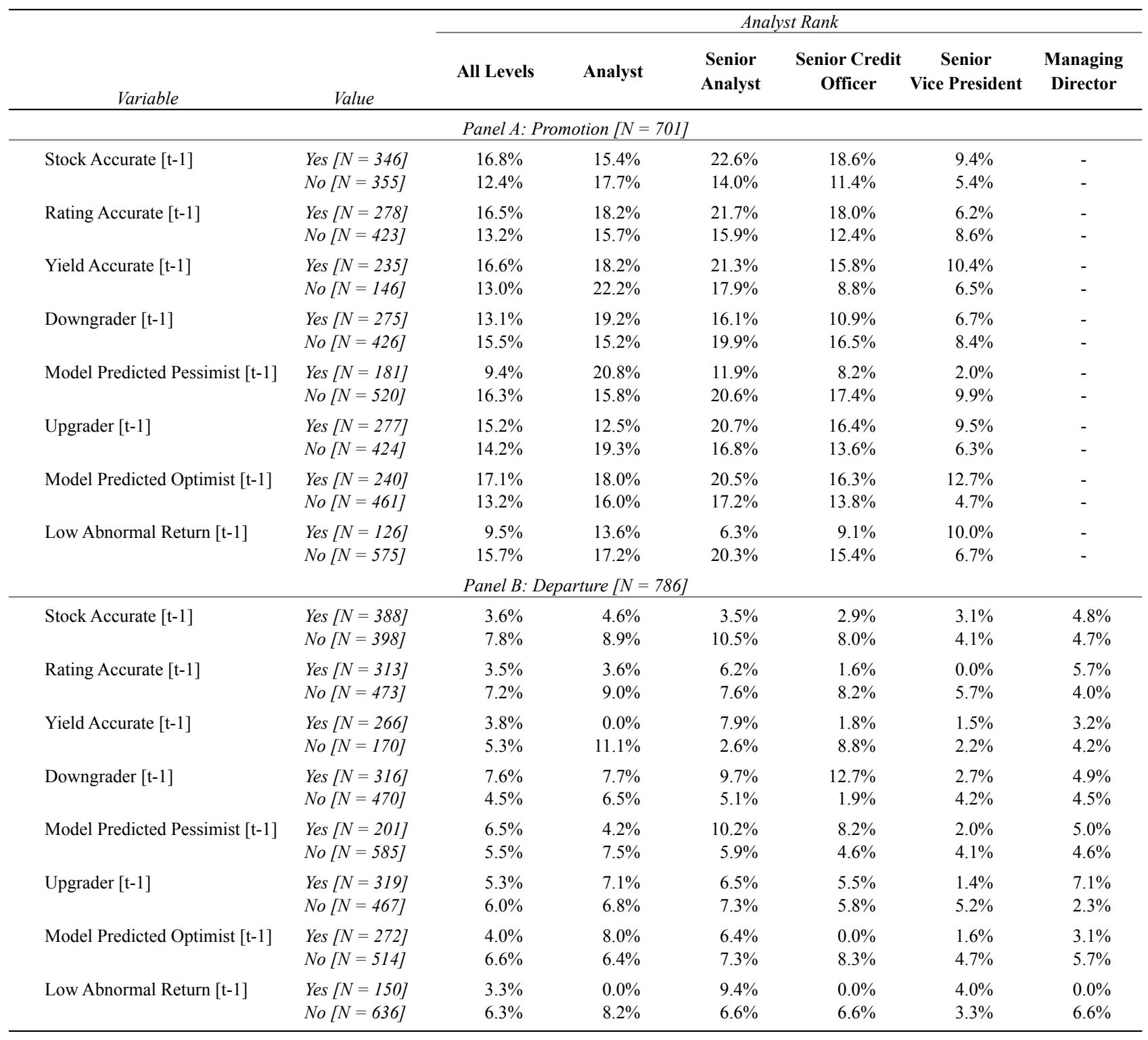




\section{Appendix Table A-3}

\section{Accuracy, Pessimism, and Optimism}

This table reports ordered logit and logit specifications analogous to those estimated in Table 7, except that we now include the Optimist Index. The absolute values of Z-statistics are reported below the coefficients, where ***, **, and * denote statistical significance at the 1 percent, 5 percent, and 10 percent levels, respectively, based on heteroskedasticity-robust standard errors that are clustered by analyst.

\section{Panel A. Full Sample}

\begin{tabular}{|c|c|c|c|c|}
\hline \multirow[b]{2}{*}{ Explanatory Variables } & \multicolumn{2}{|c|}{ Ordered Logit: Career Path [t] } & \multicolumn{2}{|c|}{ Logit: Promoted [t] } \\
\hline & {$[1]$} & {$[2]$} & {$[3]$} & {$[4]$} \\
\hline Accuracy Index [t-1] & $\begin{array}{c}\mathbf{1 . 8 5 0} * * * \\
(4.100)\end{array}$ & $\begin{array}{c}1.865 * * * \\
(3.933)\end{array}$ & $\begin{array}{c}1.565 * * * \\
(2.656)\end{array}$ & $\begin{array}{l}1.529 * * \\
(2.246)\end{array}$ \\
\hline Pessimist Index [t-1] & $\begin{array}{c}\mathbf{0 . 5 6 5} * * * \\
(3.968)\end{array}$ & $\begin{array}{c}\mathbf{0 . 5 4 9} * * * \\
(3.812)\end{array}$ & $\begin{array}{c}\mathbf{0 . 6 1 0} * * * \\
(2.764)\end{array}$ & $\begin{array}{c}\mathbf{0 . 5 6 9} * * * \\
(2.827)\end{array}$ \\
\hline Optimist Index [t-1] & $\begin{array}{c}\mathbf{0 . 9 6 4} \\
(0.316)\end{array}$ & $\begin{array}{c}\mathbf{0 . 9 2 4} \\
(0.631)\end{array}$ & $\begin{array}{c}\mathbf{1 . 0 1 5} \\
(0.106)\end{array}$ & $\begin{array}{c}\mathbf{0 . 9 5 2} \\
(0.320)\end{array}$ \\
\hline Calendar Year FEs? & -- & Yes & -- & Yes \\
\hline Analyst Rank * Years in Rank FEs? & -- & Yes & -- & Yes \\
\hline$N$ & 786 & 786 & 701 & 701 \\
\hline Pseudo R-Squared & 0.028 & 0.095 & 0.030 & 0.137 \\
\hline
\end{tabular}

Panel B. Excludes career outcomes for 2008 and 2009

\begin{tabular}{lcccccc} 
& \multicolumn{2}{c}{ Ordered Logit: Career Path [t] } & & \multicolumn{2}{c}{ Logit: Promoted [t] } \\
\cline { 2 - 3 } \cline { 5 - 6 } \cline { 5 - 6 } Explanatory Variables & {$[1]$} & {$[2]$} & & {$[3]$} & \multicolumn{2}{c}{$[4]$} \\
\cline { 1 - 3 } Accuracy Index [t-1] & $\mathbf{2 . 0 1 7 * * *}$ & $\mathbf{1 . 9 8 2 * * *}$ & & $\mathbf{1 . 6 4 6 * *}$ & $\mathbf{1 . 5 9 9 * *}$ \\
& $(3.856)$ & $(3.571)$ & & $(2.479)$ & $(2.056)$ \\
Pessimist Index [t-1] & $\mathbf{0 . 5 6 2 * * *}$ & $\mathbf{0 . 5 4 9 * * *}$ & & $\mathbf{0 . 6 1 8 * *}$ & $\mathbf{0 . 5 6 2 * *}$ \\
& $(3.316)$ & $(3.278)$ & & $(2.376)$ & $(2.532)$ \\
Optimist Index [t-1] & $\mathbf{0 . 9 5 3}$ & $\mathbf{0 . 9 1 8}$ & & $\mathbf{1 . 0 3 3}$ & $\mathbf{0 . 9 4 9}$ \\
& $(0.326)$ & $(0.525)$ & & $(0.179)$ & $(0.255)$ \\
$N$ & 563 & 563 & & 499 & 480 \\
Pseudo R-Squared & 0.032 & 0.090 & & 0.024 & 0.122 \\
\hline
\end{tabular}

Panel C. Excludes senior vice presidents (SVP) and managing directors

\begin{tabular}{|c|c|c|c|c|}
\hline \multirow[b]{2}{*}{ Explanatory Variables } & \multicolumn{2}{|c|}{ Ordered Logit: Career Path [t] } & \multicolumn{2}{|c|}{ Logit: Promoted [t] } \\
\hline & {$[1]$} & {$[2]$} & {$[3]$} & [4] \\
\hline Accuracy Index [t-1] & $\begin{array}{c}1.893 * * * \\
(4.097)\end{array}$ & $\begin{array}{c}\mathbf{1 . 9 5 8}^{* * * *} \\
(4.079)\end{array}$ & $\begin{array}{c}\mathbf{1 . 5 8 8}^{* * * *} \\
(2.654)\end{array}$ & $\begin{array}{c}1.609 * * \\
(2.407)\end{array}$ \\
\hline Pessimist Index [t-1] & $\begin{array}{c}\mathbf{0 . 5 7 2} * * * \\
(3.473)\end{array}$ & $\begin{array}{c}\mathbf{0 . 5 3 0} * * * * \\
(3.561)\end{array}$ & $\begin{array}{c}\mathbf{0 . 6 6 8}^{* *} \\
(2.169)\end{array}$ & $\begin{array}{c}\mathbf{0 . 5 9 6 * *} \\
(2.411)\end{array}$ \\
\hline Optimist Index [t-1] & $\begin{array}{c}\mathbf{0 . 9 4 4} \\
(0.436)\end{array}$ & $\begin{array}{c}\mathbf{0 . 8 3 6} \\
(1.224)\end{array}$ & $\begin{array}{c}\mathbf{0 . 9 7 2} \\
(0.175)\end{array}$ & $\begin{array}{c}\mathbf{0 . 8 2 7} \\
(1.033)\end{array}$ \\
\hline$N$ & 531 & 531 & 531 & 531 \\
\hline Pseudo R-Squared & 0.032 & 0.086 & 0.020 & 0.127 \\
\hline
\end{tabular}




\section{Appendix Table A-4}

\section{Accuracy Versus Bias Controlling for $(\log )$ Level of Rated Assets}

This table reports ordered logit and logit specifications analogous to those estimated in Table 7, except that we now control for the natural logarithm of the level of rated assets in year $\mathrm{t}-1$. The absolute values of $\mathrm{Z}$-statistics are reported below the coefficients, where $* * *, * *$, and $*$ denote statistical significance at the 1 percent, 5 percent, and 10 percent levels, respectively, based on heteroskedasticity-robust standard errors that are clustered by analyst.

\section{Panel A. Full Sample}

\begin{tabular}{lcccccc} 
& \multicolumn{2}{c}{ Ordered Logit: Career Path $[t]$} & & \multicolumn{2}{c}{ Logit: Promoted $[t]$} \\
\cline { 2 - 3 } \cline { 5 - 6 } Explanatory Variables & {$[1]$} & {$[2]$} & & {$[3]$} & {$[4]$} \\
\hline Accuracy Index [t-1] & $\mathbf{1 . 7 8 4 * * *}$ & $\mathbf{1 . 7 2 1 * * *}$ & & $\mathbf{1 . 5 1 8 * *}$ & $\mathbf{1 . 4 0 9 *}$ \\
& $(4.066)$ & $(3.519)$ & & $(2.570)$ & $(1.797)$ \\
Pessimist Index [t-1] & $\mathbf{0 . 5 5 2 * * *}$ & $\mathbf{0 . 5 2 2} * * *$ & & $\mathbf{0 . 5 9 0 * * *}$ & $\mathbf{0 . 5 4 6 * * *}$ \\
& $(4.161)$ & $(4.136)$ & & $(2.977)$ & $(2.998)$ \\
Log Rated Assets [t-1] & $\mathbf{1 . 0 8 8}$ & $\mathbf{1 . 2 2 0} * * *$ & & $\mathbf{1 . 1 5 5 *}$ & $\mathbf{1 . 3 5 1 * * *}$ \\
& $(1.477)$ & $(2.761)$ & & $(1.928)$ & $(2.809)$ \\
Calendar Year FEs? & -- & Yes & & -- & Yes \\
Analyst Rank * Years in Rank FEs? & -- & Yes & & -- & Yes \\
$N$ & 786 & 786 & & 701 & 701 \\
Pseudo R-Squared & 0.030 & 0.099 & & 0.028 & 0.146 \\
\hline
\end{tabular}

Panel B. Excludes career outcomes for 2008 and 2009

\begin{tabular}{|c|c|c|c|c|}
\hline \multirow[b]{2}{*}{ Explanatory Variables } & \multicolumn{2}{|c|}{ Ordered Logit: Career Path [t] } & \multicolumn{2}{|c|}{ Logit: Promoted $[t]$} \\
\hline & {$[1]$} & {$[2]$} & {$[3]$} & {$[4]$} \\
\hline Accuracy Index [t-1] & $\begin{array}{c}1.940 * * * \\
(3.843)\end{array}$ & $\begin{array}{c}1.834 * * * \\
(3.285)\end{array}$ & $\begin{array}{l}1.608 * * \\
(2.526)\end{array}$ & $\begin{array}{l}\text { 1.453* } \\
(1.694)\end{array}$ \\
\hline Pessimist Index [t-1] & $\begin{array}{c}\mathbf{0 . 5 4 7} * * * * \\
(3.442)\end{array}$ & $\begin{array}{c}\mathbf{0 . 5 0 6 * * *} \\
(3.640)\end{array}$ & $\begin{array}{c}\mathbf{0 . 5 9 5} * * * \\
(2.586)\end{array}$ & $\begin{array}{c}\mathbf{0 . 5 3 7} * * * \\
(2.733)\end{array}$ \\
\hline Log Rated Assets [t-1] & $\begin{array}{c}\mathbf{1 . 1 0 7} \\
(1.454)\end{array}$ & $\begin{array}{c}1.286 * * * \\
(3.047)\end{array}$ & $\begin{array}{l}\text { 1.179* } \\
(1.772)\end{array}$ & $\begin{array}{c}1.442 * * * \\
(2.784)\end{array}$ \\
\hline$N$ & 563 & 563 & 499 & 480 \\
\hline Pseudo R-Squared & 0.035 & 0.102 & 0.032 & 0.145 \\
\hline
\end{tabular}

Panel C. Excludes senior vice presidents (SVP) and managing directors (MD)

\begin{tabular}{|c|c|c|c|c|}
\hline \multirow[b]{2}{*}{ Explanatory Variables } & \multicolumn{2}{|c|}{ Ordered Logit: Career Path [t] } & \multicolumn{2}{|c|}{ Logit: Promoted $[t]$} \\
\hline & {$[1]$} & [2] & {$[3]$} & {$[4]$} \\
\hline Accuracy Index [t-1] & $\begin{array}{c}1.785 * * * \\
(3.721)\end{array}$ & $\begin{array}{c}1.773 * * * \\
(3.481)\end{array}$ & $\begin{array}{l}1.490 * * \\
(2.291)\end{array}$ & $\begin{array}{l}\text { 1.416* } \\
(1.743)\end{array}$ \\
\hline Pessimist Index [t-1] & $\begin{array}{c}\mathbf{0 . 5 5 1} * * * \\
(3.756)\end{array}$ & $\begin{array}{c}0.512 * * * \\
(3.781)\end{array}$ & $\begin{array}{c}\mathbf{0 . 6 5 2} * * \\
(2.329)\end{array}$ & $\begin{array}{c}\mathbf{0 . 5 8 1} * * \\
(2.498)\end{array}$ \\
\hline Log Rated Assets [t-1] & $\begin{array}{c}1.287 * * * \\
(3.474)\end{array}$ & $\begin{array}{c}1.311 * * * \\
(3.044)\end{array}$ & $\begin{array}{c}1.335 * * * \\
(3.404)\end{array}$ & $\begin{array}{c}1.382 * * * \\
(2.887)\end{array}$ \\
\hline$N$ & 531 & 531 & 531 & 531 \\
\hline Pseudo R-Squared & 0.047 & 0.098 & 0.042 & 0.143 \\
\hline
\end{tabular}

